\title{
«VUESTRA MADRE» DE LA SANTA MONTAÑA EN SAN LORENZO, PUERTO RICO: ¿LA ARTICULACIÓN DEL MITO DE LA VIRGEN MARÍA EN LA PERSONA DE ELENA ACHE?*
}

\author{
POR
}

\author{
Gerardo Alberto Hernández Aponte \\ Universidad de Puerto Rico
}

\begin{abstract}
A mi amiga y colega Marisol Martínez Fuentes
...dado el momento de madurez intelectual en que nos encontramos, no hay que dar lugar a meras suposiciones y elucubraciones mentales. [...] Hay que dejar de lado las imaginaciones... para situarnos lo más posible dentro del plano histórico. Hoy día la historiografía ha llegado a tal punto de rigor y seriedad científica que resulta deshonesto no tenerla en cuenta a la hora de hablar... ${ }^{1}$

...si algo demuestran los estudios de religiones comparadas es que la originalidad de una experiencia mística reside precisamente en su ahistoricidad. Nada impide que la universalidad de una misma vivencia... pueda expresarse, en diferentes tiempos y culturas... ${ }^{2}$

...los modelos de interpretación de tales «hombres y mujeres extraordinarios» se han trasformado con el correr del tiempo... ${ }^{3}$
\end{abstract}

${ }^{*}$ Este artículo es un adelanto de una investigación en curso. Agradecemos al Dr. Arturo V. Dávila Rodríguez, quién siendo Consultor de la Pontificia Comisión para la conservación del patrimonio artístico e histórico de la Iglesia Católica en Puerto Rico nos brindó estímulo para redactar este ensayo.

Siglas

ABH: Archivo del padre Jaime M. F. Reyes, OSB en la Abadía Benedictina de Humacao

AHA: Archivo Histórico Arquidiocesano

AHD: Archivo Histórico Diocesano

${ }^{1}$ García Paredes, José Cristo Rey, 2001. Mariología: XVII Madrid, España, Biblioteca de Autores Cristianos. La palabra en bastardilla se encuentran así en el original.

${ }^{2}$ Mujica Pinilla, Ramón, 2001. Rosa limensis. Mística, política e iconografía en torno a la patrona de América: 171. Lima, Perú, Instituto Francés de Estudios Andinos; Fondo de Cultura Económica S. A. de C. V.; Banco Central Reserva del Perú.

${ }^{3}$ Linse, Ulrich, 2002. Videntes y milagreros. La búsqueda de la salvación en la era de la industrialización: 12. Madrid, España, Siglo Xxi de España Editores, S. A. 


\title{
RESUMEN
}

Este artículo explora la vida y las teorías acerca de la identidad de una misteriosa mujer que vivió entre 1899-1909 en el área sureste de Puerto Rico y que era conocida por sus seguidores por el apodo de «Vuestra Madre». En este ensayo expondremos una nueva hipótesis sobre su identidad. Por otro lado, analizaremos cómo se fue construyendo un mito en torno a su persona y cómo este ha ido evolucionando hasta el presente representando un verdadero reto para la jerarquía católica.

PalAbras ClaVE: Mito, anacoreta, Virgen María, Madre Elenita, Hermanos Cheos.

\section{«VUESTRA MADRE» OF THE HOLY MOUNTAIN IN SAN LORENZO, PUERTO RICO: THE ARTICULATION OF THE MYTH OF THE VIRGIN MARY IN THE PERSON OF ELENA ACHE? *}

\begin{abstract}
This article explores the life and theories about the identity of a mysterious woman who lived from 1899-1909 in the area southeast of Puerto Rico and was known to her followers by the nickname of «Vuestra Madre». This essay will discuss a new hypotesis about her identity. In addition, we analyze how a myth was built up around her person and how its evolution poses up to present times a real problem for the Catholic hierarchy.
\end{abstract}

Key words: Myth, anchorite, Virgin Mary, Mother Elenita, Hermanos Cheos

$\begin{array}{ll}\text { Recibido/Received } & 30-08-2010 \\ \text { Aceptado/Accepted } & 27-03-2014\end{array}$

\section{INTRODUCCIÓN}

A fines del siglo XIX y a principios del XX vivió en Puerto Rico una mujer conocida como «Vuestra Madre», quien llevó a cabo prácticas ascéticas. Hasta hoy, su vida ha estado involucrada en una atmósfera de misterio y controversia por desconocerse su identidad y por haberse formado un mito en torno a ella, que la clasificó como una aparición mariana en Puerto Rico. Según Mircea Eliade, los mitos son aquellas explicaciones que proporcionan modelos de conducta humana y confieren valor a la existencia de quienes lo creen. ${ }^{4}$ Algunas

\footnotetext{
${ }^{4}$ Eliade, Mircea, 1968. Mito y realidad: 14. Madrid, España, Ediciones Guadarrama, S. A.
} 
personas creyeron y aún creen que esta enigmática mujer era en realidad la Virgen María quien en cuerpo y alma había bajado a Puerto Rico para convivir y ayudar espiritualmente a los campesinos del área sureste de la Isla.

En este artículo examinamos dos puntos convergentes que se entrelazan entre sí. Primero, exponemos una nueva teoría acerca de quién era «Vuestra Madre». Contextualizamos e interpretamos su surgimiento y modus vivendi para entender de forma holística su persona y su quehacer religioso. Seguidamente, explicamos cómo se fue articulando un mito en torno a ella y cómo este ha ido evolucionado a través de los años hasta la actualidad. La mitologización de dicha mujer ha presentado un problema para la jerarquía de la diócesis de Caguas $^{5}$ por los errores doctrinales que, según la misma, conlleva creer que «Vuestra Madre» era en realidad la Virgen María.

\section{CONTEXTO HISTÓRICO}

Previo a entrar de lleno en su vida, es preciso entender y conocer el contexto histórico en que se desarrolló la obra evangelizadora de esta mujer. La invasión de Estados Unidos de América a Puerto Rico, ocurrida el 25 de julio de 1898, trajo numerosos cambios en la sociedad puertorriqueña particularmente en la religiosidad del país. La Iglesia Católica, Apostólica y Romana en Puerto Rico fue una de las instituciones que recibió con mayor fuerza su impacto. ${ }^{6} \mathrm{La}$ institución tuvo que enfrentarse, entre otras cosas, a una separación de Iglesia y de Estado y a una libertad de culto jurídica y abiertamente establecida y predicada por las autoridades estadounidenses, especialmente diseñada como política oficial del Presidente William McKinley a favor de las nuevas misiones protestantes. La libertad de culto, que de modo limitado existía desde 1869, trajo consigo que diversas iglesias protestantes se agruparan por regiones en el país, de manera que para 1905 todos los pueblos contaban con al menos una congregación protestante. Así, emprendieron una cruzada misionera anticatólica para «protestantizar» a Puerto Rico. Los pobladores rurales propiciaron un terreno fértil para el protestantismo. Los ministros y pastores protestantes exponían que Estados Unidos era portador del progreso, de la «civilización» y de los valores democráticos frente al régimen hispánico, identificado con la miseria, el oscurantismo y la explotación. Dentro de ese contexto la Iglesia Católica fue tildada

\footnotetext{
${ }^{5}$ Esta diócesis fue creada el 4 de noviembre de 1964 por la Bula Quod Munus del Papa Pablo VI y comprende parte del área geográfica donde llevó a cabo la obra evangelizadora «Vuestra Madre».

${ }^{6}$ Hernández Aponte, Gerardo Alberto, 2013. La Iglesia Católica en Puerto Rico ante la invasión de Estados Unidos de América. Lucha, sobrevivencia y estabilización: (1898-1921): 105-141. San Juan, Puerto Rico: Academia Puertorriqueña de la Historia y Decanato de Estudios Graduados e Investigación (DEGI) de la Universidad de Puerto Rico, Recinto de Río Piedras.
} 
como cómplice del atraso de las colonias españolas debido a que se le asociaba al «antiguo régimen» por haber estado unida al Estado desde los inicios de la colonización de Puerto Rico. Por tal razón, no era extraño que el gobierno estadounidense tratara por todos los medios de reducir la influencia de la Iglesia Católica en beneficio del protestantismo y enfilara sus cañones sobre ella.?

En la Isla se suscitó entonces una experiencia inesperada que mantuvo en la Iglesia Católica a gran parte de los habitantes rurales: los predicadores laicos. ${ }^{8}$ Estos, aunque al principio no tuvieron el visto bueno de la Iglesia Católica, provocaron no solo multitud de frutos espirituales sino también asombro, desconfianza e incertidumbre por parte de muchos sacerdotes. Con el tiempo algunos de estos predicadores se asociaron y se llamaron Hermanos Cheos o Congregación de San Juan Evangelista. Fueron personas que, en la mayoría de los casos, sin tener educación escolar se lanzaron a predicar a favor de la Iglesia Católica, combatiendo el protestantismo, el concubinato, el alcoholismo y el adulterio, entre otras situaciones. ${ }^{9}$ Estos predicadores aseguraban estar asistidos o favorecidos en la prédica por algún santo en específico. De ahí que muchos creyentes pensaron que eran santos venidos para predicar desde la eternidad. ${ }^{10}$

${ }^{7}$ Ibídem, 105-114; Silva Gotay, Samuel, 1997. Protestantismo y política en Puerto Rico 1898 1930: hacia una historia del protestantismo evangélico en Puerto Rico, Río Piedras, P. R., Editorial de la Universidad de Puerto Rico; Pantojas García, Emilio, [1973-1985?]. La iglesia protestante y la americanización de Puerto Rico, 1898-1917, Bayamón, P. R., Prisa; Cambell, Michael «"Imperialismo sin un imperio colonial": misioneros protestantes en Puerto Rico: 1898-1914» en Ricardo R. Camuñas (ed.), El impacto del 1898 en el oeste puertorriqueño: 66-68. San Juan, P. R., Librería y Editorial Ateneo Puertorriqueño.

${ }^{8}$ Estos campesinos se adelantaron proféticamente a los decretos del Concilio Vaticano II, en el que se reconocerían las capacidades y los carismas otorgados por el Espíritu Santo a los laicos. Es importante destacar que aún hoy día los laicos no pueden dar la homilía, pues es una función reservada al sacerdote o al diácono. Sin embargo, están autorizados a cooperar en la prédica siempre y cuando tengan una preparación adecuada y cónsona al magisterio católico. Véase al respecto: Santaella Rivera, Esteban, 2003 Historia de los Hermanos Cheos. Recopilación de escritos y relatos: 74, 182-185 y 374. Rincón, P. R., MB Publishers de Puerto Rico; Concilio Vaticano II. Constituciones, decretos, declaraciones, legislación posconciliar: 94-107. Madrid, España: Biblioteca de Autores Cristianos, 1967, artículos 30-38 de la Constitución dogmática Lumen gentium; Código de Derecho Canónico. Edición bilingüe comentada por los profesores de la facultad de Derecho Canónico de la Universidad Pontificia de Salamanca: 397-398 y 400-401. Madrid, España, Biblioteca de Autores Cristianos, 1984, cánones 759 y 766-767; Abad Ibáñez, J. A. y M. Garrido Bonaño, 1997. Iniciación a la liturgia de la Iglesia: 402 Madrid, España, Ediciones Palabra.

${ }^{9}$ Santaella Rivera, Esteban, 2003: xiii, 71, 78, 102 y 142; Vázquez González, Ángel M., 1986. El Paso por la Vega: 97 y 105. México: Editorial Tierra Firme, S. A., de C. V.; El Ideal Católico, 30 de marzo de 1901, p. 387; Westmeier, Karl-Wilhelm, 2000. El dolor y la gloria: una historia de la Alianza Cristiana y Misionera en Puerto Rico: 54-55 Philadelphia, EE. UU., Christian Publications Inc.; El Defensor Cristiano, 1 de febrero de 1906, p. 1.

${ }^{10}$ Santaella Rivera, Esteban, 2003: 64, 70-71, 78, 119, 135, 137, 165, 175, 192, 196 y 198; Vázquez González, Ángel M., 1986: 101-103; Boletín Eclesiástico de la Diócesis de Puerto Rico, 20 de junio de 1910, p. 194; Vicario, Francisco, 1909. «Apuntes para la historia de la Congregación de la Misión en

Hispania Sacra, LXVI

134, julio-diciembre 2014, 689-731, ISSN: 0018-215X, doi: 10.3989/hs.2014.066 


\section{TEORÍAS ACERCA DE LA IDENTIDAD DE «VueStRa MADRE»}

Las mujeres fueron las pioneras en el campo de la predicación. Una de ellas fue conocida como «Vuestra Madre», ${ }^{11}$ y sobre ella, hace varios años, existen múltiples teorías acerca de su identidad. Según consta en el acta de defunción, su nombre era Elena Huge, hija de Emilio H. Huge; pero no hay datos objetivos que den cuenta de su procedencia y del nombre de su progenitora. ${ }^{12}$

En 1994, el padre José Dimas Soberal Díaz, secretario ejecutivo del Centro de Estudios de los Dominicos del Caribe (CEDOC), estableció la hipótesis de que podría tratarse de una tal Helena Huyke, miembro de la familia Huyke, establecida en Arroyo hacia el $1874 .{ }^{13}$ Sin embargo, Estela Cifre de Loubriel, en su estudio sobre los extranjeros en el Puerto Rico decimonónico, probó en 1962 que Elena Huyke ${ }^{14}$ vivió en Arroyo en 1874, era profesora y contaba con veinticinco años. Asimismo, expuso que tiempo después abandonó la Isla. ${ }^{15}$ Además, según la documentación consultada sabemos que Elena Huyke murió en Curazao el 3 de diciembre de $1927 .{ }^{16}$

Según, el profesor de sociología, Pedro J. Rivera Arbolay, algunas personas aseguraban que su nombre era Magdalena. ${ }^{17}$ Varios testigos tenían la convicción de que ella era literalmente la «Virgen María», que había venido del cielo para ayudarles..$^{18}$ De esta manera, siguieron apareciendo teorías sobre su procedencia. ${ }^{19}$ Sin embargo, el exalcalde de San Lorenzo, el licenciado y contable,

la isla de Puerto Rico» en Anales de la Congregación de la Misión fundada por San Vicente de Paúl, tomo XVII: 623 Madrid, España, Imprenta del Asilo de Huérfanos del S. C. de Jesús; La Verdad, 4 de octubre de 1913, p. 616.

${ }^{11}$ Santaella Rivera, Esteban, 2003: 48-71, 78-79 y 165.

${ }^{12}$ Ibídem, pp. 65-66; Reyes, Jaime M. F., 1991. La Santa Montaña de San Lorenzo, Puerto Rico, y el misterio de Elenita de Jesús (1899-1909): 193-195. México, Tipografías Editoriales.

${ }^{13}$ Soberal, José Dimas, 1994. La Santa Montaña: investigación realizada para la Conferencia Episcopal Puertorriqueña: 55-57 y 77. Bayamón, P. R., texto inédito en los archivo del padre Jaime M. F. Reyes, OSB en la Abadía Benedictina de Humacao (en adelante ABH).

${ }^{14}$ Así aparece el nombre escrito en los estudios sobre su persona.

${ }^{15}$ Cifre de Loubriel, Estela, 1962. Catálogo de extranjeros residentes en Puerto Rico en el siglo XIX: 20. Río Piedras, P. R.: Ediciones de la Universidad de Puerto Rico.

${ }^{16} \mathrm{Su}$ nombre completo fue Maria Catharina Helena Huyke nacida el en Curazao el 6 de octubre de 1847. Era hija de Bernardus Hendrikus Josephus Huyke y de Maria Ignis Blan. Véase: Fotocopia del acta de defunción de Maria Catharina Helena Huyke en holandés y su traducción al español hecha por el sacerdote Dr. Félix Struik O. P. ambos en ABH.

${ }^{17}$ Rivera Arbolay, Pedro J., 1977. Patillas, la esmeralda del sur: 57-58. San Juan, P. R., Cooperativa de Artes Gráficas «Romualdo Real».

${ }^{18}$ Santaella Rivera, Esteban, 2003: 50; Reyes, Jaime M. F., 1991: 24.

${ }^{19}$ Reyes, Jaime M. F., 1991: 27-29. 
católico y masón, Ramón Fortuño Sellés,$^{20}$ alega, en un artículo publicado en 1935, haberla conocido personalmente y asegura que su nombre era Elena Ache, natural de Humacao e hija de un tonelero de Islas Vírgenes. Además, él asegura que a los diez años quedó huérfana y Felipe Chandri Roura y Juana Torres Ortiz la recogieron y la ingresaron en Beneficencia donde permaneció por más de diez años. En este mismo artículo, Fortuño Sellés reconoce que «Vuestra Madre» fue un personaje enigmático para los moradores del casco urbano de San Lorenzo. Según él, muchos se cuestionaban quién era aquella dama. Ante el misterio que rodeaba a su persona, él afirma que se dedicó a investigar sobre su vida y procedencia. ${ }^{21}$

Esta enigmática mujer era llamada por sus seguidores: Misionera, Elenita de Jesús, la Virgen, Vuestra Madre y Vuestra Madre Redentora. ${ }^{22}$ Su radio de acción comprendió los municipios de Caguas, Yabucoa, Las Piedras, San Lorenzo, Cayey, Guayama y Patillas. ${ }^{23}$

Desde el punto de vista de la documentación histórica consultada hasta el momento, de todas las hipótesis expuestas, la de Ramón Fortuño Sellés resulta ser la más convincente. Primero, por los datos específicos que él ofreció sobre las personas que recogieron a «Vuestra Madre». La evidencia documental encontrada muestra que el catalán Felipe Chandri Roura procreó, ilegítimamente con Juana Torres Ortiz, una hija llamada Petra Carmen. Esta última nació el 8 de mayo de 1883 y fue reconocida por Chandri Roura el 22 de noviembre de 1889. ${ }^{24}$ Segundo, en Beneficencia, el lugar donde «Vuestra Madre» fue ingresada, conoció a las Hijas de la Caridad, quienes eran las encargadas del

\footnotetext{
${ }^{20}$ Asenjo, Conrado, 1941-1942. «Quien es quien en Puerto Rico». Diccionario biográfico de récord personal: 91. San Juan, P. R., Cantero Fernandez \& Co. Asenjo expuso, en vida de Fortuño Sellés, que el fue alcalde del pueblo; sin embargo, hasta ahora no hemos encontrado ningún libro de historia del pueblo de San Lorenzo que reconozca su desempeño como alcalde. Quizás se deba a que el 31 de mayo de 1937 se incendió la alcaldía de dicho pueblo perdiéndose toda la documentación. Véase al respecto: «El ayuntamiento de San Lorenzo destruido por un fuego en la madrugada de ayer» en El Mundo, 1 de junio de 1937.

${ }^{21}$ Fortuño Sellés, Ramón, «Elena Ache "Vuestra Madre"» en El Mundo, 19 de junio de 1935, 9 y 15 .

${ }^{22}$ Reyes, Jaime M. F., 1991: 49-52; San Juan News, 20 de mayo de 1904, 4.

${ }^{23}$ Reyes, Jaime M. F., 1991: 32-47; Rivera Arbolay, Pedro J., 1977: 57-58; Rodríguez, Paulino, 1967. Historia del pueblo de Patillas: 163. Hato Rey, P. R., Ramallo Bros. Printing, Inc.

${ }^{24}$ Archivo Parroquial de Nuestra Señora de las Mercedes del pueblo de San Lorenzo, Libro de bautismos tomo 17, folio 223v., partida número 1342; Archivo General de Puerto Rico, Fondo: Departamento de Estado, Tarea 74-14, Serie: Declaraciones de Nacionalidad, caja 6, legajo San Juan Catedral Núm. 6, 3389-3957, folio 3408; Sarramía, Tomás, 1999. Lealtad y nacionalidad. Catálogo de catalanes, valencianos y baleares residentes en Puerto Rico tras el cambio de soberanía de 1898: 58. San Juan, P. R., PR Books.
}

Hispania Sacra, LXVI

134, julio-diciembre 2014, 689-731, ISSN: 0018-215X, doi: 10.3989/hs.2014.066 
lugar. ${ }^{25}$ Es posible que «Vuestra Madre» fuera la mujer que la prensa espiritista menciona que fue vista en 1902 en Cayey, vestida a semejanza de una Hija de la Caridad, exhortando a contraer matrimonio católico y a reprobar el civil. ${ }^{26}$ Además, la prensa de la época publicó que las personas que la conocían aseguraban que ella había vivido en comunidad con las Hijas de la Caridad. ${ }^{27}$ Tercero, los datos específicos ofrecidos sobre «Vuestra Madre» coinciden con las fuentes primarias y los testimonios orales recogidos, por el presbítero Jaime Reyes Maldonado, entre aquellos que la conocieron. Por ejemplo, Fortuño Sellés señala que ella recogía limosnas entre las personas pudientes para repartirlas entre los pobres. ${ }^{28}$ Reyes Maldonado expuso que las limosnas eran utilizadas para ayudar a los necesitados y para pagar los estipendios de los sacramentos. ${ }^{29}$ La prensa señaló que las recogía pero que se desconocía a qué las dedicaba ella. ${ }^{30}$ Tanto Fortuño Sellés como los testimonios orales coinciden en el hecho de que el cuerpo de «Vuestra Madre» fue conducido en un ataúd de cristal hasta la necrópolis. ${ }^{31}$

Por otro lado, presumimos que la «H.» que aparece como inicial de un segundo nombre del padre de Elena Huge en el acta de defunción sea en realidad una equivocación. En otras palabras, que la persona que registró la defunción en vez de poner «Ache» como apellido, entendió que era la letra «h» como inicial de un nombre. De esta forma, Ache sería el apellido paterno de «Vuestra Madre» y Huge el materno de su progenitor. Tenemos que recordar que «Ache» no es un apellido común en Puerto Rico, aunque sí se conoce. Asimismo sabemos que las personas que registraban los nacimientos y defunciones solían escribir los nombres según el sonido de pronunciación y no con la ortografía correcta que debían llevar. Un caso similar sucede con el apellido «Power» que es pronunciado «Pover» y también como «Págüer» de ahí que en la documentación el apellido aparezca escrito de diversas maneras. ${ }^{32}$ Siguiendo este planteamiento hemos

${ }^{25}$ Quiñones Rivera, Sor Ursula y Sor Candida Quiñones Rivera, 1983. Las Hijas de la Caridad en Puerto Rico: 1863-1983: 16-18. Santo Domingo, R. D., Amigo del Hogar; Rivera Rivera, Antonia, 1995. El estado español y la beneficencia en el Puerto Rico del siglo XIX: 222-223 Republica Dominicana, Editorial El Cuervo Dorado; «Una inspirada por la Vírgen (sic) en San Lorenzo» en La Correspondencia de Puerto Rico, 16 de diciembre de 1906, 1.

${ }^{26}$ El Iris de Paz, 12 de julio de 1902.

${ }^{27}$ «Una inspirada por la Vírgen (sic) en San Lorenzo» en La Correspondencia de Puerto Rico, 16 de diciembre de 1906, 1 .

${ }^{28}$ Fortuño Sellés, Ramón, 1935: 9.

${ }^{29}$ Reyes, Jaime M. F., 1991: 27.

${ }^{30}$ «Hay en Patillas una religiosa que predica el evangelio» en La Correspondencia de Puerto Rico, 21 de diciembre de 1903.

${ }^{31}$ Fortuño Sellés, Ramón, 1935: 15; Reyes, Jaime M. F., 1991: 107.

${ }^{32}$ Picó, Fernando, 1997. «De Póver a Págüer: La configuración del personaje en la narrativa histórica en Puerto Rico» en Carmen Cazurro García de la Quintana y Mario R. Cancel Sepúlveda (eds.), Enfoques generacionales/Rumbos postmodernos: 39. Aguadilla, P. R., Quality Printers. 
encontrado en Puerto Rico siete apellidos cuya ortografía es similar a Ache y estos son: Hache, ${ }^{33}$ Haché, ${ }^{34}$ Hasche, ${ }^{35}$ Harches, ${ }^{36}$ Jache, ${ }^{37}$ Arche ${ }^{38}$ y Arché ${ }^{39}$ En definitiva el asunto de la delimitación del apellido merece más investigación.

El hecho de que el padre José Dimas Soberal Díaz supusiese que el apellido «Huge» fuera en realidad «Huyke», por ser el único que guarda similitud en los registros parroquiales, de los pueblos que ella realizó su obra, no resulta convincente. Primero, porque ya la historiadora Cifre de Loubriel expuso que ella abandonó la Isla. Segundo, la edad que ella tenía en 1874 no cuadra con la que aparece en el acta de defunción y la evidencia documental demuestra que ella falleció años después. Finalmente, entendemos que de acuerdo a la pronunciación del apellido no se puede colegir tal hipótesis. El apellido Huyke es pronuncia como «jeike», «juike», «jiuk» y «juik». Por estas razones resultaría dudoso que alguien pudiera escribirlo como Huge cuando este último se pronuncia «jiuge». Dadas las señas de identidad ofrecidas por Ramón Fortuño Sellés habría que probar que Elena Ache no era «Vuestra Madre», así como se comprobó que Helena Huyke era otra persona.

\section{Obra de «Vuestra Madre» en el sureste de Puerto Rico}

«Vuestra Madre» fue vista por primera vez el 8 de agosto de 1899, día en que atravesó la Isla el huracán San Ciriaco ${ }^{40}$ y no solo atrajo a muchos campe-

${ }^{33}$ La Correspondencia de Puerto Rico, 3 de septiembre de 1894, 3; La Democracia, 11 de octubre de 1894, p. 3; González Mendoza, Juan R., 2002. «Revolución ecológica y desarrollo de las haciendas en San Germán, 1750-1850» en Mario R. Cancel y Héctor R. Feliciano Ramos, (editores). Invitación a la historia regional: 55. San Juan de Puerto Rico, Asociación Puertorriqueña de Historiadores, Postdata.

${ }^{34}$ Puerto Rico Ilustrado, 29 de enero de 1927, p. 53; 9 de marzo de 1929.

${ }^{35}$ Boletín Mercantil de Puerto Rico, 26 de mayo de 1889, p. 3; Revista de Puerto Rico, 17 de mayo de 1889

${ }^{36}$ La Correspondencia de Puerto Rico, 9 de febrero de 1901, 2.

${ }^{37}$ Ibídem, 27 de septiembre de 1895, 3.

${ }^{38}$ Boletín Mercantil de Puerto Rico, 27 de marzo de 1889, 3.

${ }^{39}$ La Correspondencia de Puerto Rico, 5 de junio de 1895, 3; 8 de agosto de 1895, 3; 21 de agosto de 1906, p. 2; 22 de septiembre de 1906, p. 2; El Nuevo Día, 29 de noviembre de 2004, 89.

${ }^{40}$ Sobre dicho huracán véase: Aráez y Ferrando, Román, 1905. Historia del ciclón del día de San Ciriaco. Resúmen (sic) general de cuanto fué (sic) observado por el autor de esta obra, y publicado por la prensa periodística de la Isla de Puerto Rico, sobre lo acontecido en esta el 8 de agosto de 1899, en que pasó un terrible huracán, resultando la muerte violenta de 2.184 de sus habitantes é hiriendo 2.764, más causando daños materiales en la propiedad por valor de \$35.889,013, San Juan, P. R., Heraldo Español; Rosario Rivera, Raquel (ed.), 2000. La llegada del cíclope: percepciones de San Ciriaco a cien años de su visita, San Juan, P. R., Fundación Puertorriqueña de las Humanidades; Salivia, Luis A., 1972. Historia de los temporales de Puerto Rico y las Antillas (1492 a 1970): 242-257. San Juan, P. R., Editorial Edil, Inc.; Schwartz, Stuart B., 1992. «El huracán de San Ciriaco: Desastre, política y sociedad en Puerto Rico 1899-1901» en Historia y sociedad, año 5, 1992: 128-162.

Hispania Sacra, LXVI

134, julio-diciembre 2014, 689-731, ISSN: 0018-215X, doi: 10.3989/hs.2014.066 
sinos a la fe católica, sino que, además, les enseñó a leer y a escribir. ${ }^{41}$ Alentó la práctica de recitar oraciones incluyendo aquellas que forman parte del acervo de la piedad popular. Fortuño Sellés menciona que los seguidores de «Vuestra Madre» recitaban salmos y oraciones junto a ella. ${ }^{42}$ Varias de sus oraciones fueron recogidas por el sacerdote Reyes Maldonado, y algunas son producto de la religiosidad popular puertorriqueña, la cual, a su vez, es heredera de la española. Por ejemplo, la oración de exorcismo y del Magnificat, que «Vuestra Madre» enseñó a sus discípulos, ${ }^{43}$ han sido encontradas por Teodoro Vidal Santoni en diversas áreas de la geografía insular con algunas variantes. ${ }^{44}$ Además, las «Doce Palabras» que ella enseñó a sus seguidores ${ }^{45}$ también fueron encontradas por Vidal Santoni y Justo Pastor Ruiz en Puerto Rico ${ }^{46}$ y por el etnógrafo español Jesús Suárez López en España. ${ }^{47}$

Según Fortuño Sellés, desde su ascenso a la montaña practicó el ayuno con tanta rigurosidad que al parecer cayó en un estado de demencia.$^{48}$ Un corresponsal periodístico de la época afirmó que ella se autoproclamó la Virgen María, y así se lo comunicó a sus seguidores ${ }^{49}$ Por este motivo no nos extraña que uno de los predicadores laicos, llamado José de los Santos Morales, expresara:

...el tercero día de aquella gran tormenta el 8 de Agosto, le concedió Cristo N. A. R. á su Santísima Madre sus santas inspiraciones por 7 años para enviarles á este mundo á resplandecer su santísima moral que oculta y vituperiada la tenían debajo de la piedra del ceremil, pues el día 27 de Enero próximo es el día determinado de María Santísima entregar á su divino hijo las santas inspiraciones, si María Purísima alcanza quedarse con ellos por un tiempo más, nada sucederá, pero si son entregadas tengan cuidado que puede suceder cualquier cosa, puede haber desprendimiento de estrellas ó puede caer una lluvia caliente, ó trasladarse un cometa y fultear con esta tierra ó haber una tiniebla, sabréis vuestros hermanos que los Padres son más rigurosos que las madres, pues sabréis que se acerca el momento de ser recogidas las inspiraciones, están en los tiempos de terminados (sic)... ${ }^{50}$

\footnotetext{
${ }^{41}$ Reyes, Jaime M. F., 1991: 29, 32, 42 y 85-91.

${ }^{42}$ Fortuño Sellés, Ramón, 1935: 15.

${ }^{43}$ Reyes, Jaime M. F., 1991: 111-119.

${ }_{44}^{44}$ Vidal, Teodoro, 2010. Oraciones, conjuros y ensalmos en la cultura popular puertorriqueña: 56-61. San Juan P. R., Ediciones Alba; (del mismo autor),1989. Tradiciones en la brujería puertorriqueña: 81-82, 187-190. San Juan P. R., Ediciones Alba.

${ }^{45}$ Reyes, Jaime M. F., 1991: 91-92.

${ }^{46}$ Vidal, Teodoro, 2010: 55-57; (del mismo autor),1989: 84; Pastor Ruiz, Justo, 1947. Vieques antiguo y moderno. 1493-1946: 185. Yauco, Puerto Rico, Tipografía Rodríguez Lugo.

${ }^{47}$ Suárez López, Jesús, 2009. Cuentos medievales en la tradición oral de Asturias: 247-257. Asturias, España, Red de Museos Etnográficos de Asturias.

${ }^{48}$ Fortuño Sellés, Ramón, 1935: 15.

49 «"Yo la Admirable y Respetable Madre Redentora del Universo". Así se moteja ella misma una mujer de Patillas, en el barrio de Rio (sic) Arriba» en La Correspondencia de Puerto Rico, 7 de abril de 1908 , p. 3.

${ }^{50}$ El Defensor Cristiano, 1 de noviembre de 1906, 2.
} 
Cada predicador espontáneo tuvo un santo que, según ellos, los favorecía o inspiraba. Es menester aclarar que cuando ellos predicaban decían que no eran ellos los que hablaban, sino un santo en específico. Por este motivo, se autodenominaban con nombre de santos ${ }^{51}$ El ejemplo lo tenemos en José de los Santos Morales Rodríguez que en una de sus prédicas expresó: «Yo soy Juan Evangelista que llego hasta este pecador por medio de un hilo...» ${ }^{52}$ Siguiendo este patrón, en el caso de «Vuestra Madre» la inspiración sería la Virgen María. El hecho de autoproclamarse la Virgen María nació de la inspiración que alegaba recibir de la Madre de Dios. ${ }^{53}$

Según un corresponsal del periódico La Correspondencia de Puerto Rico en 1908, ya «Vuestra Madre» se proclamaba la Virgen María a través de una hoja suelta que supuestamente hizo imprimir y circular. El texto del volante transcrito en la prensa era:

«Yo, la Angélica Aurora ordeno que solo las niñas se acerquen á la montaña y que si vienen de otros pueblos mujeres, se estén bastante lejos, para que no impida (sic) mis actos.

«Yo la Admirable y Respetable Madre Redentora del Universo, lo que deseo es que solo las personas de respeto se acerquen á mí, dándome el tratamiento de redentora.

Patillas, barrio de Rio (sic) Arriba, 30 de Marzo de 1908.

«Yo la Admirable y Reverendísima Madre Redentora.- Tip. de Alvarez. (sic) Guayama». ${ }^{54}$

Dicho corresponsal afirmó que le escandalizó la circulación de este escrito porque a su juicio sus seguidores le rendían culto. Además, lo calificó de tener visos de panteísmo o de «neurosis mística». Sostuvo que ella explotaba a sus seguidores y castigaba a niños y hombres, imponiéndoles penitencias y trabajos respectivamente. Expresó que sería bueno que la prensa de Puerto Rico divulgara estos hechos para que las autoridades del país trataran de combatir el fanatismo religioso que invadía las costumbres de los campesinos. ${ }^{55}$

${ }^{51}$ Boletín Eclesiástico de la Diócesis de Puerto Rico, 20 de junio de 1910, p. 194; El Defensor Cristiano, 1 de febrero de 1906, 2; El Ideal Católico, 23 de marzo de 1901, 378; Santaella Rivera, Esteban, 2003: 71.

${ }^{52}$ El Defensor Cristiano, 1 de febrero de 1906.

53 «Una inspirada por la Vírgen (sic) en San Lorenzo» en La Correspondencia de Puerto Rico, 16 de diciembre de 1906,1 .

${ }^{54}$ «"Yo la Admirable y Respetable Madre Redentora del Universo”. Así se moteja ella misma una mujer de Patillas, en el barrio de Rio (sic) Arriba» en La Correspondencia de Puerto Rico, 7 de abril de 1908 , p. 3. Las palabras en bastardilla y las comillas se encuentran así en el original.

${ }^{55}$ Ídem.

Hispania Sacra, LXVI

134, julio-diciembre 2014, 689-731, ISSN: 0018-215X, doi: 10.3989/hs.2014.066 
«Vuestra Madre» murió en su casa del barrio Espino de San Lorenzo a los treinta y cinco años, el 29 de septiembre de 1909, según el acta de defunción, a causa de debilidad general. ${ }^{56}$ Testigos oculares afirmaron que la encontraron muerta en un charco de sangre. ${ }^{57}$ Las dos versiones coinciden con los síntomas de tuberculosis, enfermedad que al parecer ella padecía, pues otro de sus síntomas, la inapetencia era característico de su persona. ${ }^{58}$ Fue enterrada a los tres días, en el cementerio municipal de San Lorenzo. ${ }^{59}$ Un sanlorenceño protestante que presenció el entierro expresó:

Yo presencié, el entierro de aquella embrutecida mujer que llamaban «Redentora madre Elena,» cuyo cadáver velaron mas (sic) tiempo del que la ley autoriza... y en estado de putrefacción y con pestilentes nauseabundas emanaciones, fué paseado procesionalmente por el pueblo, hasta el cementerio. Sucediéronse las mas enérgicas protestas, pero sin resonancia, sin eco, completamente mudas. ${ }^{60}$

Este testimonio contrasta con el de una testigo que asegura que su cuerpo emanaba olor a rosas ${ }^{61}$ durante el primer día de velación.

\section{Semejanza con los anacoretas de la Edad Antigua}

El modus vivendi de «Vuestra Madre» era similar al de los anacoretas de la antigüedad. Hasta ahora todo parece indicar que ella deseó ser religiosa pero, por alguna razón, no pudo ingresar a ninguna congregación. Quizás se debió a su color de piel, pues en el acta de defunción se señala que era trigueña. ${ }^{62}$ En aquella época existía el prejuicio racial en algunas congregaciones religiosas y en el clero secular. ${ }^{63}$ Por este motivo, asumió una vida eremítica que combinó con la predicación porque se percató de la ignorancia espiritual del campesinado del área este de Puerto Rico. Sus penitencias y ayunos eran muy similares a la de los anacoretas. «Vuestra Madre», a semejanza de las colonias

\footnotetext{
${ }^{56}$ Santaella Rivera, Esteban, 2003: 65- 66; Reyes, Jaime M. F., 1991: 193-195.

${ }^{57}$ Santaella Rivera, Esteban, 2003: 55; Reyes, Jaime M. F., 1991: 106.

${ }^{58}$ Lebrón Rivera, Rafael, 1990. ¡Detengamos el jinete de la muerte!: la lucha por controlar la tuberculosis en Puerto Rico, 1900-40...: 79-80. Tesis de Maestría, Río Piedras, Universidad de Puerto Rico, Departamento de Historia.

${ }^{59}$ Fortuño Sellés, Ramón, 1935: 15.

${ }^{60}$ La Conciencia Libre, 5 de noviembre de 1911, 5. Las palabras en bastardilla se encuentran así en la fuente.

${ }^{61}$ Reyes, Jaime M. F., 1991: 106.

${ }^{62}$ Ibídem, p. 194.

${ }^{63}$ Carroll, Henry King, 1975. Report on the Island of Porto Rico, Its Population, Civil Government, Commerce, Industries Production, Roads, Tariff, and Currency, with Recommendations: 655-656. Nueva York, EE. UU., Arno Press; Sáez, José Luis, 1994. La Iglesia y el negro esclavo en Santo Domingo. Una historia de tres siglos: 42 y 60-65. Santo Domingo, República Dominicana, Patronato de la Ciudad Colonial de Santo Domingo.
} 
monacales, tenía un grupo de niñas vírgenes a las, que entre otras cosas, enseñó a orar. La diferencia radicó en que ellas no se dedicaron a la vida ascética ni entraron a formar parte de congregación religiosa alguna.$^{64}$ Otro aspecto fue el autoproclamarse la «Virgen María», bien producto de su fantasía enfermiza o a consecuencia lógica del culto que le rendían sus seguidores. En la historia eclesiástica existen ejemplos de ermitaños que llegaron a creerse casi Dios. La soberbia y la excesiva veneración que le tributaban sus seguidores eran denominadores comunes. ${ }^{65}$ Un ejemplo fue el primer anacoreta de Indias, Gregorio López (1542-1596), quien hubo temporadas que rehusó la confesión y la eucaristía, ${ }^{66}$ al parecer, porque creía haber alcanzado la perfección espiritual y, por consiguiente, no necesitaba recibir los sacramentos. Otro de ellos fue el ermitaño Valens, quien, según expresó, Jesucristo se le había aparecido y lo había alabado por sus virtudes, y por este motivo alegó que no le era menester comulgar. ${ }^{67}$ Este aspecto se reflejó también en la vida de «Vuestra Madre» ya que los testigos aseguran que nunca la vieron asistir a la celebración de la misa dominical. ${ }^{68}$ Se podría también ver cierta semejanza entre la presencia de errores teológicos en los anacoretas, y, si se interpreta literalmente, el hecho de que, según uno de los documentos encontrados, ella se hace llamar «Madre Redentora del Universo». ${ }^{69}$ La teología católica establece que Cristo es el único redentor del género humano y único mediador ante Dios Padre; y María es una sierva especial del misterio de la Redención. Este papel María lo asumió subordinada a Jesús, pero nunca a su mismo nivel o grado.$^{70}$ No obstante, es importante exponer que la parroquia del pueblo de San Lorenzo tiene por patrona a Nuestra Señora de las Mercedes. ${ }^{71}$ En esta advocación mariana propia de la Orden de la Merced, la Virgen María recibe el calificativo de redentora. ${ }^{72}$ De hecho en una novena impresa en el país y dedicada a dicha advocación existe un himno a ella cuya última estrofa lee:

\footnotetext{
${ }^{64}$ Reyes, Jaime M. F., 1991: 121-122.

${ }^{65}$ Gómez Carillo, E. «Introducción» en Paladius, Los padres del desierto: XXII y XXV. París, Francia, Casa Editorial Garnier Hermanos.

${ }^{66}$ Mujica Pinilla, Ramón, 2001: 100 y 102-103.

${ }^{67}$ Paladius: 85-87.

${ }^{68}$ Reyes, Jaime M. F., 1991: 87-88.

${ }^{69}$ "“Yo la Admirable y Respetable Madre Redentora del Universo". Así se moteja ella misma una mujer de Patillas, en el barrio de Rio (sic) Arriba» en La Correspondencia de Puerto Rico, 7 de abril de 1908,3 .

${ }^{70}$ González, Carlos Ignacio, 1989. María Evangelizada y Evangelizadora: 351-355. Bogotá, Colombia, Consejo Episcopal Latinoamericano (CELAM); Catecismo de la Iglesia Católica: 116. Santo Domingo, República Dominicana, Librería Juan Pablo II, 1992, canon 494.

${ }^{71}$ Rodríguez León, Mario A., 1990. Los registros parroquiales y la microhistoria demográfica en Puerto Rico: 348. San Juan, P. R.: Centro de Estudios Avanzados de Puerto Rico y el Caribe.

${ }^{72}$ Novena de la Purísima Virgen María de la Merced, y Misericordia, Redentora de los cautivos. Para implorar su gran protección en cualquier necesidad espiritual ó temporal: 1, 3, 8, 10-11 y 13. San Juan, Tip. De González \& Co., 1888.
}

Hispania Sacra, LXVI

134, julio-diciembre 2014, 689-731, ISSN: 0018-215X, doi: 10.3989/hs.2014.066 


\section{A Vos Lucero del dia (sic) \\ Invocamos por Redentora \\ Hacednos merced María \\ De ser nuestra Protectora. ${ }^{73}$}

Es menester aclarar que el sentido que la novena, la orden religiosa y la Iglesia Católica aplican a la palabra Redentora es la relación especial que existe con el único mediador Jesucristo. Dicho de otro modo que María redimió al género humano unida a Cristo por el sufrimiento que experimentó durante su pasión; además por aceptar ser la madre del redentor. Por esta razón el papa Benedicto XV, quien fue el primer pontífice que formuló la doctrina de la corredención, expuso que las gracias de la redención vienen a través de la Virgen María. Este mismo Papa expuso que María es la mediadora de todas las gracias debido a que redimió al mundo junto a Jesucristo. Por estas razones a María se le ha llamado la nueva Eva, y ella aunque asociada al nuevo Adán, está sujeta a él. ${ }^{74}$ Además, el papa Benedicto XVI el 13 de mayo de 2010 en su saludo a los enfermos en el Santuario de Fátima les dijo: «Vosotros seréis redentores en el Redentor, como sois hijos en el Hijo. ${ }^{75}$ Habría pues, que determinar cuidadosamente los matices implícitos en el uso de la palabra redención en todo lo concerniente a «Vuestra Madre», a la luz del magisterio eclesial.

«Vuestra Madre» pidió que se acercaran a ella dándole el trato de redentora. ${ }^{76}$ La teología católica establece que María, la Madre de Dios, por ser Madre del Verbo Encarnado, su primer deber era dar a conocer, amar y adorar a su hijo Jesucristo y no la reclamación del culto a sí misma. ${ }^{77}$ Otro asunto parecido es que su expresión de «dar el cambio», para referirse al proceso de su muerte, ${ }^{78}$

${ }^{73}$ Ibídem.

${ }^{74}$ Carroll, Eamon R., 1964. «María en el magisterio de la Iglesia» en J. B. Carol, Mariología: 39, 40 y 42. Madrid, España, Biblioteca de Autores Cristianos; Carol, Juniper B., «Corredención de nuestra Señora» en Ibídem, 762-763, 765-766 y 768; Robichaud, Armand J. «María, dispensadora de todas las gracias» en Ibídem, 810-811.

${ }^{75}$ Homilía del Santo Padre Benedicto XVI, 13 de mayo de 2010 en la explanada del Santuario de Fátima como parte del Viaje Apostólico a Portugal en el $10^{\circ}$ aniversario de la beatificación de Jacinta y Francisco, los pastorcillos de Fátima (11-14 de mayo de 2010). Consultada en http://www.vatican.va/

76 «"Yo la Admirable y Respetable Madre Redentora del Universo". Así se moteja ella misma una mujer de Patillas, en el barrio de Rio (sic) Arriba» en La Correspondencia de Puerto Rico, 7 de abril de 1908,3 .

${ }^{77}$ Carrillo, Salvador, 1988. «El mensaje teológico de Guadalupe» en Nuestra Señora de América. Homenaje del CELAM a la Santísima Virgen, con motivo del Año Mariano, tomo II: 71. Bogotá, Colombia, Consejo Episcopal Latinoamericano (CELAM).

${ }^{78}$ Reyes, Jaime M. F., 1991: 50, 103-104. 
es una frase idiomática del espiritismo de Allan Kardec..$^{79}$ Este atisbo a una doctrina ajena a la católica es cónsono con el hecho de que ella predicó en casa del espiritista Manuel Muñoz residente en el barrio Lajitas de Caguas..$^{80}$

Nos serviría de punto de referencia exponer que durante la Edad Antigua, al ser admitidos a la vida monástica, se les enseñaba a los monjes lo indispensable dentro del marco religioso, sin instruírseles en la cultura general. Esta ignorancia crasa trajo como consecuencia innumerables problemas de índole herético. Una de las herejías surgidas fue el mesalianismo, el cual consistía principalmente en dejarse guiar por fenómenos espirituales en vez de la doctrina de la Iglesia Católica. Con el tiempo, la Iglesia se vio precisada a legislar para que los monjes estuviesen bajo la jurisdicción de la jerarquía eclesiástica. Así, pues, la Iglesia durante la celebración del Concilio de Calcedonia, en 451, se propuso administrar adecuadamente dicha institución. El monacato entonces fue organizado jurídicamente por la jerarquía eclesial. En última instancia, lo que la legislación eclesiástica perseguía era que el obispo de cada región pudiera tener potestad de aprobar o negar la fundación de monasterios y supervisar a su vez el comportamiento de los monjes. ${ }^{81}$ De este modo se corregían las desviaciones en materia de fe y de vida que no fueran cónsonas con el magisterio eclesial católico. La supervisión era imprescindible en los ermitaños o anacoretas pues, en ocasiones, eran presos de ilusiones o exageraciones en su modus vivendi, al punto de poner en riesgo su vida. El freno del fanatismo, de mistificaciones y de los abusos que tanto mal hacen a la religión era necesario imponerlo en un ambiente donde había terreno fecundo para ello. ${ }^{82}$

«Vuestra Madre» no fue un caso aislado en Puerto Rico. En agosto de 1903, apareció en el barrio San José de Quebradillas una mujer que causó gran revuelo en la población, pues varias personas aseguraban que la Virgen se había aparecido sobre una peña, con una paloma sobre la cabeza y un halo de luz a su alrededor. Se rumoraba que llevaba varios días sin comer y que dormía sobre las piedras del bosque. Un corresponsal del periódico La Correspondencia de Puerto Rico que la entrevistó dijo que era una mujer sin educación, trigueña y que decía llamarse María Luisa Ramos, oriunda de Guayanilla. Sin embargo,

\footnotetext{
${ }^{79}$ Rodríguez Escudero, Néstor A., 1994. El angustioso enigma de la muerte, su más razonable hipótesis: el espiritismo kardeciano científico: 180. Quebradillas, P. R., Imprenta San Rafael; Hernández Aponte, Gerardo Alberto, 2010. El espiritismo de Allan Kardec en Puerto Rico 1860-1907: 418. Tesis doctoral, Río Piedras, Universidad de Puerto Rico, Departamento de Historia.

${ }^{80}$ Reyes, Jaime M. F., 1991: 32, 34, 37.

${ }^{81}$ Colombás, García M., 1974. El monacato primitivo. Hombres, hechos, costumbres, instituciones, tomo I: 182-183, 307-338. Madrid, España, Biblioteca de Autores Cristianos de La Editorial Católica, S. A.

${ }^{82}$ Llorca, Bernardino, Ricardo García-Villoslada, Francisco Javier Montalbán, 1966. Historia de la Iglesia Católica en sus cuatro grandes edades: Antigua, Media, Nueva, Moderna, tomo I: 606-609. Madrid, España, Biblioteca de Autores Cristianos.
}

Hispania Sacra, LXVI

134, julio-diciembre 2014, 689-731, ISSN: 0018-215X, doi: 10.3989/hs.2014.066 
al preguntarle nuevamente su nombre con el fin de redactar la noticia ella dijo llamarse María Antonia Milarié. A juicio del corresponsal la mujer era una alucinada histérica. Luego del acontecimiento ella se dedicó a labores domésticas en el Boarding House de Felipa Medina de López. ${ }^{83}$

\section{LA ARTICULACIÓN DEL MITO}

El historiador de las religiones Mircea Eliade expuso que los mitos proporcionan a sus creyentes un patrón o modelo a seguir y le dan valor y significado a la existencia de ellos, es decir, el mito justifica su modus vivendi y le ofrece sentido a su cosmovisión. El mito es considerado sagrado y verdadero por sus seguidores, es un modo de expresión, un lenguaje. Las intuiciones, los conocimientos y las creencias son expresados a través de él. Es la síntesis que irradia sus conocimientos. Mediante el mito se expresa aquellas vivencias que no pueden ser explicadas de forma racional. Este se transmite de generación en generación, sin elucubraciones intelectuales, pues lo más importante es su vivencia. ${ }^{84}$ Todo esto fue lo que produjo en sus seguidores, el mito que se articuló alrededor de «Vuestra Madre».

En el Puerto Rico de fines del siglo XIX, los pobladores de la ruralía se hallaban distanciados de la influencia y cuidado pastoral de la Iglesia debido a las condiciones geográficas que imperaban y que los separaban de las parroquias urbanas, además de la ausencia de una acción evangelizadora efectiva. La Iglesia no había podido cumplir a cabalidad con la estipulación de crear parroquias donde fuera necesario. Este mandato eclesiástico se basaba en una legislación canónica que establecía que ningún sacerdote debía tener a su cuidado más de ochocientos feligreses. Sin embargo, la Iglesia Católica insular no podía honrar esa medida porque no contaba con clero suficiente. En algunos lugares, la población fluctuaba entre tres mil a siete mil o más habitantes por sacerdote. Muchas personas de la ruralía, alejadas de la iglesia parroquial urbana, habían mantenido su fe a través del culto popular a los santos y mediante el sincretismo religioso. En términos doctrinales, esa religiosidad popular preocupaba a la jerarquía. ${ }^{85}$

${ }^{83}$ «Se dijo en Quebradillas que una Virgen se había mostrado de pié sobre una pena (sic) con una paloma en la mano» en La Correspondencia de Puerto Rico, 21 de agosto de 1903, p. 1; «Confirmase la sospecha de que la «Virgen» aparecida en Quebradillas es un caso de alucinación histérica» en $L a$ Correspondencia de Puerto Rico, 24 de agosto de 1903, 4; «Quebradillas» en La Correspondencia de Puerto Rico, 26 de agosto de 1903, 2; «A diestro y siniestro» en La Democracia, 22 de agosto de 1903, 4.

${ }^{84}$ Eliade, Mircea, 1968: 13-14, 17, 19, 24-25, 32-33, 163 y 165.

${ }^{85}$ Hernández Aponte, Gerardo Alberto, 2013: 52-53, 69 y 366; Picó, Fernando, 1998. «El catolicismo popular en el Puerto Rico del siglo 19» en Ángel G. Quintero Rivera (ed.), Vírgenes, magos y escapularios: imaginería, etnicidad y religiosidad popular en Puerto Rico: 152-153 y 
En 1887, el médico y cirujano Francisco del Valle Atiles planteó que la falta de instrucción religiosa, junto a una imaginación fantasiosa, hacían que los jíbaros fueran fácil presa de la superstición, la brujería, la hechicería y el espiritismo ${ }^{86}$

El historiador Ulrich Linse expone que ante una crisis histórica surgen movimientos y líderes religiosos que buscan reformar o mejorar las circunstancias ante el caos. ${ }^{87}$ La mentalidad mágico-religiosa y la presencia de elementos de superstición e ignorancia, crearon el terreno fértil para que germinara un mito religioso. La aguda crisis económica, política y social, junto a la sed del campesinado de tener una experiencia personal de Dios en su vida, hicieron que creyeran sin lugar a dudas que «Vuestra Madre» era la Virgen María. En otras palabras, los campesinos necesitaban tener más conocimiento de Dios, dentro de un ambiente de crisis y de alejamiento de la Iglesia institucional. En este contexto puede entenderse que «Vuestra Madre», a pesar de las limitaciones que hemos señalado, fue una persona que les hizo viable y accesible el conocimiento de Dios. El contacto de los jíbaros con ella les infundió conocimiento, esperanza e ilusiones. El hecho que de forma gradual se fuera identificando con la Virgen María, sirvió a sus seguidores como vehículo para conocer un poco más a Dios. El antiguo orden hispánico había sido interrumpido y cambiado considerablemente. La mentalidad del jíbaro necesitaba apoyo y ayuda que le brindara las herramientas necesarias para superar la crisis de 1898 y poder estabilizarse. En el caso de ellos, «Vuestra Madre» fue una líder carismática que los ayudó en el difícil paso de transición de un régimen autonómico a uno colonial estadounidense. Su ayuda provino desde la misma religiosidad popular junto a fantasías e ilusiones míticas. ${ }^{88} \mathrm{El}$ historiador Reinaldo L. Román expone que los Hermanos Cheos y «Vuestra Madre» afirmaron la importancia de los santos y de la Virgen María porque, en esa época, eran creencias fuertemente criticadas

155-159. San Juan,P. R., Centro de Investigaciones Sociales; UPR, Río Piedras; Centro de Investigaciones Académicas; Universidad Sagrado Corazón; Fundación Puertorriqueña de las Humanidades.

${ }^{86}$ Valle Atiles, Francisco del, 1887. El campesino puertorriqueño sus condiciones físicas, intelectuales y morales, causas que las determinan y medios para mejorarlas: 128. San Juan, P. R., Tip. de José González Font.

${ }^{87}$ Linse, Ulrich, 2002: 1-2.

${ }^{88}$ Agosto Cintrón, Nélida, 1998. «Género y discurso religioso en un movimiento carismático en Puerto Rico: la Madre Elenita de la Montaña Santa» en Silvia Álvarez Curbelo, Mary Frances Gallart, Carmen I. Rafucci, (eds.) Los arcos de la memoria: el '98 de los pueblos puertorriqueños: 200-205. San Juan, P. R., Editorial Postdata; Reyes, Jaime M. F., 1991: 85-91; Fortuño Sellés, Ramón, 1935: 9 y 15; Rodríguez, Paulino, 1967: 163; Carta del padre Pedro Puras, 6 de septiembre de 1911, en el Archivo Histórico Diocesano (en adelante AHD) del Archivo Histórico Arquidiocesano (en adelante AHA), Fondo: Diocesano, Sección: gobierno, Serie: correspondencia, Caja G-27, legajo San Lorenzo 1820-1928; McGuire, Vicente, 1965. Mosaico cagüeño. Recuerdos de la Parroquia del Dulce Nombre de Jesús Caguas, Puerto Rico: 32. San Juan, P. R., Cooperativa de Artes Gráficas Romualdo Real.

Hispania Sacra, LXVI

134, julio-diciembre 2014, 689-731, ISSN: 0018-215X, doi: 10.3989/hs.2014.066 
por los protestantes y espiritistas ${ }^{89}$ El historiador Fernando Picó sostiene que los Hermanos Cheos y otros personajes populares sirvieron como mediadores entre la Iglesia institucional y aquellos campesinos que practicaban su fe lejos de su influencia.${ }^{90}$ En este sentido, Nélida Agosto Cintrón sostiene que el simbolismo de la figura de la Virgen María asumida como identidad por «Vuestra Madre» satisfizo la demanda de amparo, protección y sostén que tuvo el campesinado de la época. Fue un claro reflejo de la maternidad virginal de María como elemento que salva a la humanidad al dar a luz al Redentor del Mundo. ${ }^{91}$ De ésta manera se articuló un mito alrededor de «Vuestra Madre» de que ella era la Virgen María.

\section{Pervivencia y DesarRollo Del Mito}

En 1901, según los testimonios recopilados por el sacerdote Jaime Reyes Maldonado, «Vuestra Madre» subió al cerro que hoy día se conoce como la Santa Montaña ${ }^{92}$ situado en el pueblo de San Lorenzo. ${ }^{93}$ Allí hizo construir una Capilla. ${ }^{94}$ En 1910 un corresponsal del diario La Correspondencia de Puerto Rico informó la existencia en el lugar de un culto a cargo de unas personas que se hacían llamar «hijitos de Vuestra Madre». Este periodista anónimo consignó que el lugar era llamado «Santa Montaña» y expuso que allí se ofrecían lo que denominaban «misiones», que era más bien unos sermones. Estas «misiones» estaban a cargo de unas personas que se autodenominaban «hermanitos». ${ }^{95}$ Ellos eran los Hermanos Cheos, quienes después de la muerte de «Vuestra Madre» continuaron su obra evangelizadora, de forma que el 21 de junio de 1917, se bendijo una nueva capilla en las inmediaciones. ${ }^{96} \mathrm{La}$ capilla fue dedicada a la Virgen del Carmen. Precisamente, «Vuestra Madre» se había identificado como la Virgen del Carmen. Además, para 1925 se acostumbraba celebrar una misión y fiesta después del primer domingo de agosto, fecha cercana al 8 de agosto, día en que los testigos alegan que «Vuestra Madre» fue vista por primera vez. El lugar era llamado la Santa Montaña porque «Vuestra Madre» había derramado

\footnotetext{
${ }^{89}$ Román, Reinaldo L., 2007. Governing Spirits. Religion, Miracles, and Spectacles in Cuba and Puerto Rico, 1898-1956: 55. North Carolina, EE.UU.: The University of North Carolina Press.

${ }^{90}$ Picó, Fernando, 1994. «Religiosidad institucional y religiosidad popular en Puerto Rico en el siglo 19» en Revista Universidad de América, año 6, núm. 2, 37.

${ }^{91}$ Agosto Cintrón, Nélida, 1998: 201.

${ }^{92}$ También se le conoce como Montaña Santa.

${ }^{93}$ Reyes, Jaime M. F., 1991: 50.

${ }^{94}$ Ibídem, p. 155; Fortuño Sellés, Ramón, 1935: 15.

${ }_{95}$ «Raros sucesos en Patillas. Feligreses de un culto que llaman de la "Santa Montaña."» en La Correspondencia de Puerto Rico, 11 de mayo de 1910, p. 1.

${ }^{96}$ Reyes, Jaime M. F., 1991: 155; Boletín Parroquial de Guayama, Pto- Rico, junio y julio de 1917, año II, núm. 6, 58-59.
} 
su sangre allí. ${ }^{97}$ De esta manera hubo una continuidad en la prédica de «Vuestra Madre» a tal punto que para 1929, San Lorenzo era conocido como la «Meca del Cristianismo en Puerto Rico». ${ }^{98}$ No fue extraño que después de su muerte, algunos de sus discípulos seguían creyendo que ella era la Virgen María. Por tal razón la Iglesia se vio precisada a esclarecer y encauzar el movimiento. ${ }^{99}$ Del mismo modo, los habitantes de los pueblos en los que «Vuestra Madre» predicó siguieron conservando de generación en generación esta creencia. Por ello no resulta extraño que asistieran a la inauguración de la Capilla en 1917. ${ }^{100}$

La realidad es que la identidad de «Vuestra Madre» es una incógnita sin resolver. En 1935, el periódico El Mundo publicó el reportaje de Ramón Fortuño Sellés que anteriormente mencionamos. Este hecho inspiró al novelista Paulino Rodríguez Bernier a terminar la novela que había comenzado en 1934 con el título de «Notre Dame». El 10 de agosto del año siguiente la finalizó y la tituló: «Elena, la misionera (leyenda patillense)», la cual publicó en 1935. ${ }^{101}$ En 1977, el profesor de sociología, Pedro J. Rivera Arbolay publicó un libro sobre el pueblo de Patillas en que expuso parte de la tradición oral que el recogió sobre «Vuestra Madre». ${ }^{102}$ En 1978, fue publicada otra leyenda sobre ella titulada «Elena de la Santa Montaña (1900)». Esta última se elaboró con los datos provistos por una maestra de San Lorenzo, Carmen Julia Vázquez de Santiago. ${ }^{103}$ Ninguno de los dos relatos señalan que ella era la Virgen María. Rodríguez Bernier la expuso como una mística y además narró que derramó su sangre cuando murió. ${ }^{104}$ Desde que Fortuño Sellés escribió el artículo aquí mencionado, al parecer, nadie había tratado con rigor el asunto salvo Rivera Arbolay. En 1979, el sacerdote Esteban Santaella Rivera publicó la primera edición de su historia sobre los Hermanos Cheos en Puerto Rico. En ella expuso información sobre «Vuestra Madre» y argumentó:

Todavía siguen creyendo los ancianitos de esos lugares que fué (sic) la misma Virgen del Carmen la que vivió con ellos en esos años. ${ }^{105}$

\footnotetext{
${ }^{97}$ Reyes, Jaime M. F., 1991: 10, 29, 106, 146, 219 y 221.

${ }^{98}$ Alarcia, R., «Desde San Lorenzo» en La Milagrosa, 11 de abril de 1929, año VIII, núm. 108, 9.

${ }^{99}$ Rodríguez, Paulino, 1967: 163; Reyes, Jaime M. F., 1991: 257.

${ }^{100}$ Boletín Parroquial de Guayama, Pto- Rico, junio y julio de 1917, año II, núm. 6, p. 58.

${ }^{101}$ Rodríguez, Paulino, 1939. Cataratas de ensueños, agosto de 1927. Don Pepillo -1920-y Elena, la misionera, 1935. Novelas cortas en 1 tomo. Aire netamente criollo: 75-93. Cayey, P. R., Imprenta Morales.

${ }^{102}$ Rivera Arbolay, Pedro J., 1977: 57-58.

${ }^{103}$ Muckley, Robert L. y Adela Martínez-Santiago, 1978. Leyendas de Puerto Rico: a Collection of Puerto Rican Legends: 59-61. Illinois, EE. UU., National Textbook Company.

${ }^{104}$ Rodríguez, Paulino, 1939: 90-92.

${ }^{105}$ Santaella Rivera, Esteban, 1979. Historia de los Hermanos Cheos. Recopilación de escritos y relatos: 46. Santo Domingo, República Dominicana, Editora «Alfa y Omega». En su segunda edición existe el mismo texto. Véase: Santaella Rivera, Esteban, 2003: 50.
}

Hispania Sacra, LXVI

134, julio-diciembre 2014, 689-731, ISSN: 0018-215X, doi: 10.3989/hs.2014.066 
En 1983, Carmen Chiesa de Pérez publicó, junto a Marcelino Canino Salgado, una leyenda titulada «Ño Goyo indio». En ella se narra la historia de una joven que vestía el hábito de las Hijas de la Caridad de San Vicente de Paúl y era llamada por los campesinos «La Santa» y «Nuestra Madrecita». Ellos pensaban que dicha joven había venido del cielo y afirmaban que era la Virgen porque la veían rezar el rosario varias veces al día. Según el relato, ella apareció muerta con sangre en su boca. De acuerdo con Chiesa de Pérez, esta leyenda está basada en la tradición oral que fue recogida en Caguas el 8 de enero de 1982 en una entrevista al poeta y periodista Pedro Millán Rivera. Según este último, «Vuestra Madre» fue una Hija de la Caridad, pero sin precisar en cuál pueblo de la geografía insular había ejercido su ministerio. También, este asegura que ella, al contagiarse con tuberculosis, se internó en los montes de Puerto Rico, bien para evitar contagiar a otros o buscar mejorar su salud. ${ }^{106}$

Es importante destacar que el artículo de Fortuño Sellés cayó en el olvido para muchos. Otros, aunque conocían la novela de Rodríguez Bernier, fueron incapaces de prestarle la debida atención o nunca pudieron conseguir el artículo periodístico de Fortuño Sellés, para proseguir la investigación. ${ }^{107}$

Así, poco a poco, el mito quedó reducido a los testigos oculares y sus familiares. Esto quedó como sustrato de la religiosidad popular existente en el área y desconocida por el resto de la población de Puerto Rico. Tal como plantea Mircea Eliade, los mitos, aunque constituyen un fenómeno importante de índole espiritual, suelen tener modestas consecuencias en el ámbito cultural por no estar escritos. Cuando la historia cultural y otras disciplinas comienzan a recopilar y analizar las creaciones del pueblo y las tradiciones orales, es que se empieza a valorizar y a tomar en consideración. Al plasmarse por escrito en un libro la herencia oral comienza a ser estudiada por diversos académicos. ${ }^{108}$ Es en este sentido que la novela de Paulino y las leyendas publicadas después contribuyeron a darle publicidad al mito. El texto del sacerdote Santaella Rivera

\footnotetext{
${ }^{106}$ Canino Salgado, Marcelino y Carmen Chiesa de Pérez, 1983. Leyendas puertorriqueñas para niños: 58-59. Hato Rey, PR.: Editorial Juvencia. En 1990 se publicó la quinta edición de esta obra.

${ }^{107}$ Paulino Rodríguez en su novela antes mencionada nos dio la pista para localizar el escrito de Ramón Fortuño Sellés. Iniciamos la búsqueda del escrito pero en ninguna de sus obras, ni en los ficheros bibliográicos del país aparecía la referencia a dicho artículo. Como la novela tenía fecha de haberse terminado de escribir el 10 de agosto de 1935, empezamos una búsqueda retrospectiva en los distintos rotativos del país. Este método de investigación consumía demasiado tiempo por lo que decidimos contactar a sus descendientes para saber si conservaban sus documentos. Nos comunicamos con Carmen D. Fortuño Candelas nieta de Fortuño Sellés y ella a su vez nos puso en contacto con su señora madre Amelia Candelas viuda de Carmelo Fortuño. Candelas viuda de Fortuño nos abrió las puertas de su hogar y nos permitió la consulta de los documentos del exalcalde de San Lorenzo. Gracias a la amabilidad y gentileza de ambas localizamos el artículo.

${ }^{108}$ Eliade, Mircea, 1968: 178-179.
} 
difundió por primera vez el hecho de que algunas personas creían que «Vuestra Madre» era la Virgen María.

\section{LA CONTROVERSIA PÚBLICA SOBRE EL MITO}

El mito recibió validez eclesial con el sacerdote benedictino Jaime Reyes Maldonado, ${ }^{109}$ quién escribió un libro titulado: La Santa Montaña de Puerto Rico. El misterio de Elenita de Jesús (1899-1909). El texto es producto de una investigación iniciada en 1978, culminada en 1991 y basada principalmente en la entrevista de ochenta personas que conocieron personalmente a «Vuestra Madre». ${ }^{110}$ La obra aborda la vida de «Vuestra Madre» a través del testimonio de los que la conocieron y es el trabajo más abarcador que existe sobre ella. El autor expuso en su escrito que muchos testigos afirmaron que «Vuestra Madre» era la Virgen María y que fueron pocos los que negaron tal versión. Sostuvo que ni la Santa Sede ni la jerarquía insular habían aprobado tal aparición. ${ }^{111}$ Sin embargo, el texto es contradictorio en sí porque en el prólogo Mons. Enrique Hernández Rivera, quien en ese entonces era el obispo de la diócesis de Caguas, expuso:

...disfrute usted la lectura de este libro, pero sin ir más allá de lo pretendido al recopilar lo que se dice y sabe de Madre Elenita, reconocida como Vuestra Madre y que también le llegaron a llamar Madre Redentora, título que nos causa extrañeza. Por favor, ora para que conozcamos la verdad sobre Madre Elenita y su obra. ${ }^{112}$

Partiendo de las palabras del prelado, creeríamos que en el texto solo se recopila información relacionada con la vida y obra de «Vuestra Madre». Sin embargo, el presbítero Reyes Maldonado afirmó que la posibilidad que se desprende de su investigación es que «Vuestra Madre» era la Virgen María, la cual se apareció de una forma especial. ${ }^{113}$ Su postura es un poco contradictoria, pues en algunos lugares del texto se inclina a pensar que lo era y en otras expresa tímidamente la mera posibilidad de que lo fuese. ${ }^{114}$

\footnotetext{
${ }^{109}$ Jaime Reyes Maldonado fue ordenado sacerdote el 30 de mayo de 1964. Posee un bachillerato en biología con concentraciones menores en química, matemáticas e idiomas de la Universidad de Puerto Rico, Recinto de Río Piedras, una Maestría en Teología, con especialidad en Liturgia, Nuevo Testamento y Patrística en Saint John's School of Theology Seminary en Minnesota. Cursó estudios doctorales en Liturgia en la University of Notre Dame en Indiana. También estudió Espiritualidad por un año en la Pontificia Universidad Católica Santo Tomás de Aquino en Roma. Véase: Maldonado Miranda, Vivian «"El hermano del beato cambió mi vida"» en El Visitante, 25 de abril al 1 de mayo de 2010,14 .

${ }^{110}$ Reyes, Jaime M. F., 1991: 7-8 y 256-320.

${ }^{111}$ Ibídem, 10, 97 y 251.

${ }^{112}$ Ibídem, 11.

${ }^{113}$ Ibídem, 31 y 257.

${ }^{114}$ Ibídem, 2; 55, 59.
}

Hispania Sacra, LXVI

134, julio-diciembre 2014, 689-731, ISSN: 0018-215X, doi: 10.3989/hs.2014.066 
Una lectura cuidadosa del texto en conjunto convencería a muchos que la persona que vivió en la Santa Montaña era la Virgen María. El sacerdote hizo un paralelismo entre la vida de «Vuestra Madre» y los hechos narrados acerca de la vida de Jesús y María por la mística italiana María Valtorta, ${ }^{115}$ quien alegadamente recibió una revelación de Dios al final de la primera mitad del siglo xx. El padre Reyes Maldonado realizó la comparación y transcribió textos del libro porque a su juicio:

....dichas revelaciones podrían ayudarnos a entender ese misterio que nos relatan los testigos oculares sobre ella. ${ }^{116}$

Para efectos de este trabajo, nos concentraremos en tres paralelismos que el sacerdote señala como prueba de que al parecer «Vuestra Madre» era la Virgen María. El autor expuso que en tres ocasiones distintas «Vuestra Madre» se convirtió en paloma. El Padre Reyes Maldonado argumentó que si María es la esposa del Espíritu Santo no existe ninguna razón teológica para que ella no se pueda convertir en paloma. Para apoyar su postulado recurrió a un pasaje de María Valtorta en que Jesús llamó a su madre: «Inmaculada Paloma de Dios». ${ }^{117}$ El segundo y tercer elemento están enlazados entre sí en el planteamiento de que la Virgen María es también Redentora de la Humanidad y que ese acto lo realizó derramando su sangre en la Santa Montaña; por este motivo, ella se llamó a si misma: «Madre Redentora». El presbítero expone que en las revelaciones a María Valtorta se dice que Jesús y María son iguales en su papel de redención y en su naturaleza humana. Asimismo, que al igual que una pareja - Adan y Eva - fueron los causantes de la culpa; Jesús y María son los redentores. Como fueron dos los pecadores se necesitaban dos víctimas propiciadoras de los pecados de la humanidad. Jesús asumió sobre sí todo el dolor de los hombres y María, el de las mujeres. La redención no culminó con la muerte de Jesús en la Cruz porque María siguió luchando contra Satanás hasta la madrugada del Domingo de la Resurrección. La tentación consistió en tratar de sembrar en ella la duda de que Jesús no resucitaría. Por otro lado, Jesús supuestamente le reveló a Valtorta que había otra redención y que no sería por medio de él, sino por su Madre. Basado en ello, el presbítero Reyes Maldonado relata que desde 1911 han estado sucediendo lacrimaciones y sangraciones en imágenes de la Virgen y de Jesucristo. Estos fenómenos han sido

${ }^{115}$ Nació el 14 de marzo de 1897 en Caserta, Italia y murió en Viareggio, Toscana el 12 de octubre de 1961 entre los años 1943 y 1950, escribió obre temas de religión. Su obra mas conocida es El Poema del Hombre Dios, donde relata la vida de Jesús y de María Santísima. Hasta ahora la posición oficial de la Iglesia Católica respecto a esta voluminosa obra es que no contiene nada en contra de su doctrina; sin embargo, esta no debe exponerse como visiones o dictados de carácter sobrenatural sino como la forma literaria de su narración de la vida de Jesús. Véase: Carta de Mons. Raymond J. Boland, Obispo de la Diócesis de Birmingham en Alabama a Mr Terry Colafrancesco, 11 de mayo de 1993 en ABH.

${ }^{116}$ Reyes, Jaime M. F., 1991: 322.

${ }^{117}$ Ibídem, 82-83 y 325 . 
aprobados por los ordinarios del lugar. Basado en todo lo anteriormente expuesto Reyes Maldonado concluye que el derramamiento de sangre por parte de «Vuestra Madre», podría entenderse como esa «Segunda Redención». ${ }^{118}$

Otro hecho medular del libro del padre Reyes Maldonado es que en este se refieren dos acontecimientos relacionados que no hemos encontrado en ninguna de la documentación previamente analizada. Primero, que ella no dijo que iba a morir sino que iba a dar un cambio. Ella le expuso a sus seguidores que si ella se iba como había venido, todos sus seguidores irían a parar a la cárcel. En este sentido algunos testigos afirman que desde cierto momento en adelante «Vuestra Madre» desapareció de la caja por lo que la enterraron vacía. ${ }^{119}$

En resumen, el sacerdote Reyes Maldonado entrevistó ochenta testigos, de los cuales la mayoría afirmó que «Vuestra Madre» era la Virgen María. Basado en los testimonios de estos testigos oculares y la lectura de las obras de María Valtorta, el padre Reyes Maldonado formuló la teoría de que «Vuestra Madre» era en realidad la Virgen María. Para completar su fundamentación, el sacerdote expone que Mons. Hernández Rivera pidió públicamente que Dios le enviase señales que ayudasen a discernir el misterio de la identidad de «Vuestra Madre». Por este motivo se transcriben tres revelaciones privadas que recibieron distintas personas, en la Isla, donde supuestamente se indica que la Virgen se manifestó e indicó que ella fue la que estuvo en la Santa Montaña. Uno de los textos fue escrito en francés, aún cuando la receptora del mensaje no conoce dicho idioma y argumentaba que estaba durmiendo cuando recibió el mandato de levantarse y escribir. ${ }^{120}$

Para efectos de este estudio, lo más importante de este libro es que se le dio publicidad y cierto apoyo eclesial a los sucesos sobre la vida de «Vuestra Madre» por ser escrito por un sacerdote y prologado por un Obispo. En otras palabras, el mito que había pasado de generación en generación era conocido por un segmento de la población y el libro de la autoría de Reyes Maldonado lo hizo de público conocimiento en la Isla. Asimismo, el hecho de ofrecer paralelismo o explicaciones basadas en las revelaciones a María Valtorta le dio respaldo, explicación y evidencia a quienes decían haberla conocido. A modo de conclusión, el libro legitimó el mito al darle credibilidad y publicidad.

El libro del padre Jaime llegó a la Isla el 8 de abril de 1992, pero entre agosto y septiembre del mismo año fue retirado de la venta por orden de Mons. Enrique Hernández Rivera. ${ }^{121}$ El Obispo alegó que el referido sacerdote en vez de pre-

\footnotetext{
${ }^{118}$ Ibídem, 15-16, 103-104, 327-328, 333-334, 336 y 338-340.

${ }^{119}$ Ibídem, 103-110.

${ }^{120}$ Ibídem, 235-253.

${ }^{121}$ Hernández Rivera, Mons. Enrique «Nota aclaratoria. En cada revisión está la fuerza del Espíritu» en El Visitante, 14 de agosto de 1993, p. 18; Comentarios del Pbro. Jaime M. F. Reyes a la investigación «La Santa Montaña» por el secretario del CEDOC (15 agosto 1994, Bayamón, Puerto Rico) en ABH.
} 
sentar información sobre «Vuestra Madre» y su obra se llenó de entusiasmo y trató de probar que ella era la Virgen María. Además, el ordinario expuso que era un error teológico llamar «redentora» a la Virgen, pues solo Cristo es considerado como el redentor de la humanidad. Asimismo objetó la utilización de la obra de María Valtorta para justificar sus opiniones. Lo mismo realizó con la palabra «materializó» que el padre Reyes Maldonado utilizó para decir que el Espíritu Santo se apareció en forma de paloma, argumentando que el magisterio eclesial nunca había enseñado eso. ${ }^{122}$

Ante la situación, el presbítero Reyes Maldonado preparó un artículo en que exponía que nunca quiso enseñar nada en contra del magisterio eclesial. Argumentó que su verdadero fin era dar a conocer la tradición que existía sobre «Vuestra Madre» entre aquellas personas que la conocieron. Sostuvo que si utilizó las revelaciones de Valtorta lo hizo para dar luz a la posibilidad de que ella fuese realmente la Virgen María. Reyes Maldonado afirmó que la utilización del título de «Madre Redentora» se hizo como parte del testimonio de los testigos, salvo en una ocasión, que lo empleó para hacerse eco de las vivencias de ellos. Explicó que el término «materializó» lo utilizó para significar que el Espíritu Santo se había aparecido en forma de paloma, tal como es narrado en el evangelio de San Lucas. Añadió que solo quiso darle nombre a esa «corporalización» de la tercera persona de la Santísima Trinidad. El sacerdote terminaba su escrito dando gracias por el celo que habían tenido corrigiendo sus errores y expuso que acogía dichas correcciones con humildad. ${ }^{123} \mathrm{El}$ artículo nunca se publicó.

Tiempo después, el presbítero José Dimas Soberal Díaz publicó un artículo en el periódico en el que dijo:

a. ¿Quién fue la Madre Elena o Vuestra Madre como algunos la llaman? ¿Acaso fue una monja?

b. ¿De dónde vino y quiénes fueron sus antepasados?

c. ¿Por qué se fue a vivir a «La Santa Montaña»?

d. ¿Acaso la Madre Elena era la Virgen María?

e. ¿Dónde está enterrada? ¿En San Lorenzo?

Pronto se publicará un libro en donde los lectores encontrarán las contestaciones a éstas y a otras preguntas. Se contestaron además, algunas ambigüedades e imprecisiones históricas contenidas en el libro escrito por el P. Jaime M. F. Reyes... ${ }^{124}$

${ }^{122}$ Hernández Rivera, Mons. Enrique, 1993: 18.

${ }^{123}$ Artículo a ser publicado en El Visitante con el visto bueno del Señor Obispo (18 agosto 1993). Explicación sobre dudas creadas por el libro de la Santa Montaña por el Rvdo. P. Jaime M. F. Reyes en ABH.

${ }^{124}$ Soberal, José Dimas, «La Santa Montaña» en El Vocero, 14 de julio de 1994, 49. 
Nunca se publicó tal libro porque no se encontró evidencia documental que descubriera quién era «Vuestra Madre» y además porque el texto presentaba dificultades metodológicas, como veremos en breve. El escrito fue presentado a la Conferencia Episcopal Puertorriqueña que asumió su supervisión, gracias a Mons. Fortunato Baldelli, quien fungía en ese entonces como Delegado Apostólico para Puerto Rico. Soberal Díaz alegó que él inició el proyecto a mitad de la década de 1980 porque Mons. Enrique Hernández Rivera le solicitó que investigara la identidad de «Vuestra Madre». El sacerdote alegó que suspendió y archivó su investigación debido a que el Obispo de la diócesis de Caguas había emitido una circular en la cual se solicitaba el respeto a los testimonios de los testigos que aseguraban que «Vuestra Madre» era la Virgen María, a la insistencia del Prelado de investigar sobre la vida del sacerdote Pedro Puras y Rábanos ${ }^{125}$ quien conoció personalmente a «Vuestra Madre», y a la publicación del libro del padre Reyes Maldonado. Ante la publicación de dicho libro la Conferencia Episcopal avaló que el presbítero Soberal Díaz finalizase su investigación. ${ }^{126}$

Según Soberal Díaz, el texto tuvo como fin identificar quién vivió en la Santa Montaña. ${ }^{127}$ Sin embargo, el análisis del documento revela que nunca se identificó tal persona. El texto señala al padre Reyes Maldonado como el creador del «mito» de que «Vuestra Madre» era la Virgen María. ${ }^{128}$ El presbítero Soberal Díaz cuestionó la capacidad mental de los ochenta testigos entrevistados por el sacerdote benedictino, aducía que ellos estaban seniles. Sostuvo que éstos habían presenciado los acontecimientos cuando tenían cinco a diez años y que por lo tanto había pasado mucho tiempo, la memoria no era fiel y exacta y podrían haber hecho cambios inconscientes de los hechos. ${ }^{129}$ Además, el padre Soberal Díaz entrevistó un solo testigo que afirma la versión contraria; es decir que «Vuestra Madre» no era la Virgen María. ${ }^{130}$

Otra manera en la que trató de minar la credibilidad de Reyes Maldonado fue el cuestionamiento de las reliquias que se conservan de «Vuestra Madre». Soberal Díaz alega que solo tuvo acceso a varias reliquias: un guante, una crucecita y un escapulario. Según el sacerdote, el análisis de esos tres objetos prueba que fueron confeccionados posterior a la muerte de «Vuestra Madre». Otra

${ }^{125}$ Nació el 19 de octubre de 1861 en Villagalijo, Provincia de Burgos, España y murió el 30 de junio de 1926 en Santurce Puerto Rico. El 12 de agosto de 1907 fue nombrado párroco del pueblo de San Lorenzo en donde ejerció su ministerio hasta el 6 de septiembre de 1912 que se le nombró a cargo de la parroquia de Loíza. Véase: Registro del personal eclesiástico de la diócesis de Puerto Rico, tomo I, fols. 250-251 en AHD del AHA, Fondo: Diocesano, Sección: gobierno.

${ }^{126}$ Soberal, José Dimas, 1994: 4-5 y 57-59. La Santa Montaña. Investigación...

${ }^{127}$ Ibídem, 59.

${ }^{128}$ Ibídem, 59, 71, 79 y 85.

${ }^{129}$ Ibídem, 7,8 y 86.

${ }^{130}$ Ibídem, 52-55.

Hispania Sacra, LXVI

134, julio-diciembre 2014, 689-731, ISSN: 0018-215X, doi: 10.3989/hs.2014.066 
reliquia adicional es del cabello de «Vuestra Madre»; Soberal Díaz aseveró que no se puede afirmar que dicho cabello pertenecía a ella. ${ }^{131}$

Soberal Díaz trató de establecer en su informe la fantasiosa hipótesis que al principio de este artículo señalamos, sobre el hecho de que «Vuestra Madre» fuera en realidad una tal Helena Huyke. Soberal Díaz no solo postuló que el Padre Reyes Maldonado creó un mito sino que malinterpretó las opiniones de éste. Ejemplo de ello es que alegó que el hecho de que Reyes Maldonado supusiera que «Vuestra Madre» era la Virgen María era sostener la creencia en la reencarnación. ${ }^{132}$ Sin embargo, de la lectura del texto del padre Reyes Maldonado nunca se desprende tal posibilidad, pues lo que él planteó fue que la Virgen se apareció en la Isla tal como lo hizo Jesús después de resucitar a los apóstoles por cuarenta días. ${ }^{133}$ Otro error que comete es llamar a la que vivió en la Santa Montaña como Helena con la consonante «h» porque supuestamente así aparece en el acta de defunción. ${ }^{134}$ Sin embargo, la evidencia documental demuestra que en el acta de defunción aparece escrita sin dicha letra. ${ }^{135}$

En resumen, en el escrito realizado por el presbítero José Dimas Soberal Díaz se acusó al sacerdote Jaime Reyes Maldonado de ser el creador del mito y contribuyó en gran medida a tergiversar sus hallazgos. Si algún error cometió el padre Reyes Maldonado fue el darle cierta validez eclesial al mito, pero nunca el crearlo, pues como hemos podido documentar este surgió a principios del siglo Xx en torno a la persona de «Vuestra Madre». Por otro lado, aunque el escrito de Soberal Díaz no se publicó, la Oficina de Medios de Comunicación Social (OMECOS) de la Diócesis de Caguas produjo en 1995 un documental titulado La Santa Montaña. Santuario de la Virgen del Carmen, donde se expuso de forma parcial algunos de sus puntos. ${ }^{136}$

Mircea Eliade plantea que los mitos se enriquecen y transforman debido a la influencia de otras culturas o a la capacidad creadora de ciertos individuos. ${ }^{137}$ Esta función fue asumida por la periodista católica puertorriqueña Vionette G. Negretti y la guaynabeña católica Reina I. Reyes quienes elaboraron un eslabón más al mito: la conspiración para desaparecer la «verdadera» identidad de «Vuestra Madre». Si bien ambos textos ofrecen la misma teoría, éstos fueron elaborados desde ópticas distintas. El texto de Negretti se titula La buenaventura y

${ }^{131}$ Ibídem, 48 y $50-52$.

${ }^{132}$ Ibídem, 71 y $79-80$.

${ }^{133}$ Reyes, Jaime M. F., 1991: 328.

${ }^{134}$ Soberal, José Dimas, 1994: 10. La Santa Montaña. Investigación...

${ }^{135}$ Copia del certificado del acta de defunción de Elena Huge publicada en: Santaella Rivera, Esteban, 2003: 65-66; Reyes. Jaime M. F., 1991: 193-195.

${ }^{136}$ «La Santa Montaña. Santuario de la Virgen del Carmen.», documental preparado por la Oficina de Medios de Comunicación Social (OMECOS) de la Diócesis de Caguas, Puerto Rico, 1995.

${ }^{137}$ Eliade, Mircea, 1968: 17. 
está escrito en forma narrativa; no obstante, la autora incluyó una bibliografía de las fuentes que alegadamente utilizó para la elaboración del texto. ${ }^{138}$ Este hecho, a nuestro juicio, le resta credibilidad al asunto. Si ella juzgó que el tema tratado era «delicado» debió haberlo hecho en forma expositiva. ${ }^{139}$ Para construir la vida de «Vuestra Madre» utilizó el texto del padre Reyes Maldonado y las memorias de Adolfo Ruiz Medina quien conoció personalmente a «Vuestra Madre». ${ }^{140}$ Negretti alega que «Vuestra Madre» se identificó como «La Buenaventura» ante Ruiz Medina. ${ }^{141}$ Sin embargo, según la señora Reina I. Reyes, Ruiz Medina quiso decir «bienaventurada». ${ }^{142}$

Negretti señala que algunas de las personas entrevistadas, - no menciona la identidad de ellas - sostienen que alguien en el pueblo inventó el apellido Huge que aparece en el acta de defunción de «Vuestra Madre» para eliminar todo vestigio de ella de los registros oficiales. ${ }^{143}$ La autora va más allá y expone que Puerto Rico es colonia de Estados Unidos de América ${ }^{144}$ y la jerarquía puertorriqueña nunca ha sido capaz de considerar la posibilidad de una aparición mariana en la Isla debido al complejo de inferioridad del colonizado. Además de esta hipótesis la autora sostiene que el asunto acerca de la identidad de «Vuestra Madre» fue eliminado como tema de investigación por las repercusiones políticas que esto conlleva. Negretti plantea que aseverar que el episodio ocurrido en la Santa Montaña a principio del siglo xx fue una aparición mariana equivale a afirmar que Puerto Rico es una nación y así Dios considera a la Isla. ${ }^{145}$ En este sentido la autora afirma que Mons. Enrique Hernández Rivera fue desbancado por, entre otras razones, el asunto del libro del padre Reyes Maldonado que él prologó. ${ }^{146}$ Para apoyar su versión la reportera expuso toda una supuesta conspi-

\footnotetext{
${ }^{138}$ Negretti, Vionette G., 2005. La buenaventura: 305 y i-xxviii. San Juan, P. R., Ediciones Yagumbro.

${ }^{139}$ Ibídem, 205.

${ }^{140}$ Ibídem, 9 y VII.

${ }^{141}$ Ibídem, 37.

${ }^{142}$ Reyes, Reina I., 2007. ;Soy Vuestra Madre! No me persigas: 76. [s.1.: s.e.].

${ }^{143}$ Negretti, Vionette G., 2005: 102-103.

${ }^{144}$ Sobre la situación colonial de Puerto Rico véase: Trías Monge, José,1999. Puerto Rico, las penas de la colonia más antigua del mundo, Río Piedras, P. R., Editorial de la Universidad de Puerto Rico, 1999; (del mismo autor), 1980-1994. Historia constitucional de Puerto Rico: V volúmenes, Río Piedras, P. R., Editorial Universitaria; Delgado Cintrón, Carmelo, 1988. Derecho y colonialismo. La trayectoria histórica del derecho puertorriqueño: ensayos, Río Piedras, P. R., Editorial Edil, Inc.; Bernabe, Rafael, 1996. Respuestas al colonialismo en la política puertorriqueña 1899-1929. Río Piedras, P. R., Ediciones Huracán, Inc.; Gould, Lyman J., 1975. La Ley Foraker. Raíces de la política colonial de los Estados Unidos, Río Piedras, P. R., Editorial Universitaria U. P. R.; Rivera Ramos, Efrén, 2001. The Legal Construction of Identity: the Judicial and Social Legacy of American Colonialism in Puerto Rico, Washington, DC, EE. UU.: American Psychological Association.

${ }^{145}$ Negretti, Vionette G., 2005: 126, 134 y 166-169.

${ }^{146}$ Ibídem: 166 y 180-181.
} 
ración para sacar a Mons. Hernández Rivera del panorama jerárquico insular, ${ }^{147}$ tema no discutido aquí por no ser inherente a la temática en estudio.

Otra manera de apoyar su tesis de que «Vuestra Madre» era la Virgen María consiste en postular que diversos videntes del mundo visitaron la Santa Montaña en la década de 1990. Entre ellos, la estadounidense Cyndi Cain, conocida como «La flor escondida del Inmaculado Corazón de María». Cain alega ser receptora de mensajes de Jesús y de la Virgen María. La autora señala como verificación que la vidente Cain afirma que luego que ella visitó la Santa Montaña recibió un mensaje en el cual la Virgen dijo haber sido «Vuestra Madre», la que vivió allí a principios del siglo xx. ${ }^{148}$ Cabe señalar que la afirmación de una vidente, no representa una comprobación definitiva de la veracidad de un hecho o de la identidad de una persona o unos acontecimientos.

Un aspecto singular del texto de Negretti es que casi al final de este se incluye las direcciones postales y electrónicas de la jerarquía insular, de la oficina de Prensa de El Vaticano y de la Congregación para las Causas de los Santos. El propósito es para que los lectores del libro pidan por medio de misivas la validación de la aparición o la investigación de este personaje histórico, para su eventual canonización en caso de no ser la Virgen María. ${ }^{149}$ La autora en cierto sentido pretende realzar la autoestima del pueblo puertorriqueño a través de sus raíces católicas a fin de demostrar que la Isla es una nación bajo un status colonial.

El escrito de Reina I. Reyes se titula ;Soy Vuestra Madre! No me persigas y es producto de más de veinticinco años de investigación. El texto se basa en la misma documentación de Negretti, además de entrevistas a ocho personas que eran hijos o parientes de algún discípulo de «Vuestra Madre». ${ }^{150}$ Este texto fue el causante de que Negretti publicara su libro porque según la señora Reyes:

Le confié unos escritos a una señora que vino a mi casa y de ahí las puertas de mi casa y de mi corazón; le proporcioné información y unos escritos para que me ayudara a redactar un libro. Esta persona abusando de mi confianza y de mi buena fe, se atrevió apoderarse de los escritos. Manipuló la investigación alterando la información a su manera y sometió un «copy right» (sic) a dichos escritos incluyendo unas memorias que no le pertenecían. Se quedó con algunos documentos que me pidió prestado, dichos documentos pertenecían a otras personas que me ayudaban. Con el robo de estos documentos, no

${ }^{147}$ Ibídem: 111-185. Sus afirmaciones carecen de la metodología propia de una investigación histórica. A veces su exposición está basada en suposiciones; además el texto revela desconocimiento del gobierno eclesial. Esto debe ser tenido en cuenta para los que en el futuro historien el episcopado de Mons. Hernández Rivera.

${ }^{148}$ Negretti, Vionette G., 2005: 123-124.

${ }^{149}$ Ibídem: 201-204.

${ }^{150}$ Reyes, Reina I., 2007: 54 y 74-150. 
sale de los medios de comunicación y de las librerías aprovechándose y lucrándose de las ventas de dicho libro. Con la alteración de los escritos, esta persona sólo ha conseguido confundir más al pueblo de Dios. Esta señora dice que quiere hacerle justicia a un obispo, pero en realidad está cometiendo una injusticia conmigo y me ha hecho un gran daño. ${ }^{151}$

Por esta razón no es extraño que ambas coincidan en la tesis de la conspiración. Reyes plantea que el nombre de «Vuestra Madre» no era Elena ya que ella se identificó como «Madre Redentora, Redención de Jesús». La autora sostiene que hubo una confabulación para desaparecer la verdadera identidad de «Vuestra Madre» y que los que realizaron tal hazaña tomaron la identidad de Elena Huyke para confundir al pueblo y tergiversar los hechos. Según ella, Huyke fue una «monja misionera protestante» que vivió en el pueblo de Arroyo. ${ }^{152}$ Por otro lado, la autora se contradice porque alega que el señor Maximino Malavé le añadió «de Jesús» al nombre de Elena; ${ }^{153}$ no obstante también le atribuye dicho hecho al padre Jaime Reyes Maldonado, exponiendo que ella entiende que él descubrió la verdad sobre la confusión creada acerca del nombre de «Vuestra Madre», pero no pudo darla a la publicidad debido que esto le afectaría grandemente por ser él un subordinado de la jerarquía eclesial. ${ }^{154}$ La autora aduce que hubo una conspiración entre librepensadores, masones, la jerarquía eclesiástica y el gobierno estadounidense para desaparecer la verdadera identidad de «Vuestra Madre». ${ }^{155}$ Cabe señalar que ella tuvo acceso a la novela de Paulino Rodríguez Bernier. En dicho texto el novelista expresó:

En estos días el distinguido escritor R. Fortuño Sellés ha escrito unas notas sobre la misionera que dice haber sido natural de Humacao y educada en un convento tenido por nombre Elena Roche. ${ }^{156}$

La señora Reyes malinterpretó el texto y creyó que «Vuestra Madre» estudió en un colegio llamado Elena Roche. ${ }^{157} \mathrm{Si}$ bien es cierto que el texto de Rodríguez Bernier tiene una errata, pues dice Roche en vez de Ache el escrito de Fortuño Sellés tenía el apellido preciso. La señora Reyes al parecer no indagó más y se quedó con lo plasmado en la obra. El texto carece de evidencia que

${ }^{151}$ Ibídem, 179. Durante nuestra investigación nos comunicamos con Reina I. Reyes para obtener fotocopia de uno de los textos que usó en el libro. Ella se negó aduciendo que eran documentos de su investigación y nos preguntó que si acudíamos de parte de Vionette G. Negretti. Al parecer la acusación que le achaca a dicha reportera es cierta.

${ }^{152}$ Reyes, Reina I., 2007: 15, 23, 103, 115, 127, 147-148, 159, 161, 173-174, 178, 182-183, 184 y $193-194,205,208,210,223,226,231$ y 235-236.

${ }^{153}$ Ibídem, 173-174.

${ }^{154}$ Ibídem, 235-236.

${ }^{155}$ Ibídem, 152-220.

${ }^{156}$ Rodríguez, Paulino, 1939: 93. Supra nota \# 107.

${ }^{157}$ Reyes, Reina I., 2007: 172-173.

Hispania Sacra, LXVI

134, julio-diciembre 2014, 689-731, ISSN: 0018-215X, doi: 10.3989/hs.2014.066 
respalde documentalmente la supuesta conspiración. Su autora sostiene que la Virgen María le encargó rescatar esta historia. ${ }^{158}$

Los escritos de la Sra. Negretti y de la Sra. Reyes avivaron la mecha de una antorcha que la jerarquía eclesiástica no ha podido apagar. Junto con la publicación de ambos textos se crearon páginas cibernéticas que exponían elementos adicionales a los publicados en los respectivos libros. ${ }^{159}$ En un intento por erradicar el mito, el periódico católico de Puerto Rico, El Visitante, publicó en la edición del 11 al 17 octubre de 2009, el resumen de una tesina del Programa de Estudios de Honor de la Universidad de Puerto Rico, Recinto de Cayey ${ }^{160}$ escrita por Militza Lozada Montañez. La misma, fue dirigida por el padre Giovanni Ruiz Esquivel, ${ }^{161}$ quien es profesor en dicho recinto y en aquel momento Rector del Santuario Virgen del Carmen en San Lorenzo. ${ }^{162}$ Dadas las circunstancias, en particular el hecho de que en febrero de 2010 este estudio fue publicado y el producto líquido de su venta donado al Santuario Diocesano Virgen del Carmen de la Santa Montaña, da la impresión de que la tesina fue un encargo con miras a tratar de solucionar la situación pastoral que enfrenta la diócesis de Caguas.

Según la autora su texto tiene seis objetivos principales. Entre ellos transcribo los tres que interesan a este estudio:

1. Presentar la historia y las creencias en el Santuario antes de la influencia y antes de la publicación del libro de Jaime Reyes, OSB.

$$
[\ldots]
$$

4. Presentar la influencia que tuvo el P. Jaime Reyes, OSB en la historia del Santuario $\mathrm{y}$ en las creencias de las personas que visitaban y que actualmente lo visitan.

$$
[\ldots]
$$

6. La investigación pretende aproximarse a lo que dice la voz oficial de la jerarquía de la Iglesia Católica con respecto a la historia y a las creencias del lugar. ${ }^{163}$

${ }^{158}$ Ibídem, 15 y $151-152$.

${ }^{159}$ A 30 de marzo de 2014 ninguna de las páginas existen. Estas fueron: soyvuestramadre.org; www. buenaventurapr.com/historia.htm. La primera fue creada el 27 de agosto de 2007 y estuvo en línea durante cinco años.

${ }^{160} \mathrm{El}$ reportaje dice que fue una tesis pero en realidad es una tesina pues en dicho recinto no se realizan disertaciones.

${ }^{161}$ El sacerdote Giovanni Ruiz Esquivel posee una Licenciatura en Filosofía de la Pontificia Universidad Católica Madre y Maestra de Santo Domingo, República Dominicana; Una Maestría en Divinidad de la Universidad Central de Bayamón, Puerto Rico y una maestría y doctorado en Psicología Clínica de la Universidad de Puerto Rico, Recinto de Río Piedras.

162 «Un siglo de historia, mitos; creencias y tradiciones religiosas de la Montaña Santa» en El Visitante, 11 al 17 de octubre de 2009, 21.

${ }^{163}$ Lozada Montañez, Militza, 2010. Un siglo de historia, mitos, creencias y tradiciones religiosas de la Montaña Santa: 17. Santo Domingo, República Dominicana, Amigo del Hogar. 
Aunque el libro pretende ser científico e imparcial, entre sus objetivos (véase núm. 6), vemos claramente que está redactado para favorecer la visión jerárquica católica respecto a la historia del lugar. ${ }^{164}$ Vemos además, que la autora parte de la premisa de que el sacerdote Reyes Maldonado tergiversó la historia del lugar, así como que reinterpretó sus tradiciones religiosas. ${ }^{165}$ Sin embargo, la autora se contradice al exponer que el padre Jaime Reyes Maldonado tergiversó los hechos pero al mismo tiempo revela que él lo que hizo fue recopilar la tradición oral de los seguidores de «Vuestra Madre». ${ }^{166}$ Asimismo lo hace al exponer el testimonio del padre Rafael Torres que dice que:

Habían algunos que creían que la Madre Elenita era la Virgen María pero la inmensa mayoría creía que era una laica, una catequista... ${ }^{167}$

Si Militza Lozada Montañez hubiera realizado una investigación más precisa, con una revisión exhaustiva de la literatura, se hubiera topado con lo que expuso en 1979 el padre Esteban Santaella Rivera, en el sentido de que los ancianos de los lugares que circunvalaban la Santa Montaña todavía creían que era la Virgen María la que los había visitado. ${ }^{168}$ Por este motivo, no resulta extraño que Paulino Rodríguez en su libro sobre historia de Patillas, publicado en 1967, expusiera al respecto:

El padre Gonzalo Noel (sic) conocía del trabajo realizado por la misionera... y quiso quitar un poco aquella idolatría. Sin hacer propaganda en contra...él se internaba en el bosque y allá en la serranía enseñaba los principios de la religión católica... ${ }^{169}$

De esta forma vemos como el sacerdote Gonzalo Antonio Noell y Aguayo ${ }^{170}$ continuó evangelizando sobre los cimientos que «Vuestra Madre» había dejado, tratando de encauzar las creencias dentro de la ortodoxia de la doctrina católica. La documentación es clara. Más aún muchos de los hallazgos realizados por el sacerdote Jaime Reyes Maldonado en su investigación se han corroborado con las fuentes primarias que hemos utilizado para la elaboración de este artículo.

${ }^{164}$ Ibídem, 103.

${ }^{165}$ Ibídem, 15-16, 31, 45, 69-70, 78 y 101-102.

${ }^{166}$ Ibídem, 29.

${ }^{167}$ Ibídem, 77. Véase también en el mismo texto la ibídem: 95.

${ }^{168}$ Supra nota \# 105.

${ }^{169}$ Rodríguez, Paulino, 1967: 163.

${ }^{170}$ Nació el 14 de junio de 1886 en Bayamón y murió el 29 de abril de 1950 en Ponce. Fue ordenado el 7 de abril de 1914 por Mons. William A. Jones. El 30 de noviembre de 1925 fue nombrado cura ecónomo de la parroquia del pueblo de Patillas. En 1927 se le designó a la parroquia de la Playa de Ponce. Véase: Registro del personal eclesiástico de la diócesis de Puerto Rico, tomo I, folios. 38-39 en AHD del AHA, Fondo: Diocesano, Sección: gobierno; Fortuño Janeiro, Luis, 1963. Álbum histórico de Ponce. Contentivo de los más importantes datos históricos y de una exposición gráfica de su cultura y progreso: 158. Ponce, P. R., Imprenta Fortuño.

Hispania Sacra, LXVI

134, julio-diciembre 2014, 689-731, ISSN: 0018-215X, doi: 10.3989/hs.2014.066 
La autora no hizo una investigación amplia y rigurosa a pesar de haber expuesto:

Por medio de una amplia revisión de literatura y entrevistas se presenta la historia y las creencias en el Santuario...171

Sin embargo, más adelante expone que: «...se hizo una breve revisión de literatura...» ${ }^{172}$ Lo cierto es que la autora se centró en los cuatro textos principales que abordan el asunto, es decir, aquellos escritos por el padre Jaime Reyes Maldonado, el presbítero José Dimas Soberal Díaz y las señoras Reina Reyes y Vionette Negretti.

La autora entrevistó a laicos y sacerdotes; los primeros, con el objetivo de ver el conocimiento que tienen acerca de la historia del lugar y a los sacerdotes, porque ellos supuestamente conocen la historia y las creencias del Santuario. ${ }^{173}$ Las entrevistas solo las realizó a aquellos sacerdotes que tuvieron contacto con el Santuario en el momento en que el sacerdote Reyes Maldonado comenzó a investigar pero no entrevistó al autor del libro. Del análisis del texto se desprende que la teoría y metodología histórica no fue tenida en consideración a la hora de elaborar el texto. Este es un asunto problemático, pues en su título y en sus objetivos pretende presentar la historia del Santuario.

La autora califica al texto del presbítero Reyes Maldonado como una novela religiosa. ${ }^{174}$ Sin embargo, lo único que hizo el sacerdote fue exponer lo que decían los testigos. El no hizo una narración sino una exposición. Su único error pudo haber sido el tratar de interpretar los datos, a fin de postular la posibilidad de que «Vuestra Madre» fuese la Virgen María. Más aún, hay que considerar el hecho de que la investigación del padre Reyes Maldonado fue rigurosa hasta el punto de haber notariado uno de los testimonios de los testigos que recopiló. ${ }^{175}$

Es menester exponer que cuando la autora evaluó el contenido de cada uno de los tres libros se propuso hacerlo desde una perspectiva histórica y eclesial. Este es uno de los puntos que denota que el estudio se torna un híbrido entre la teología y la historia. En el caso del texto del sacerdote Reyes Maldonado, señala sus «errores», utilizando los señalamientos antes expuestos y vertidos por el obispo Monseñor Hernández Rivera. En el caso de Negretti, acude a un escrito inédito facilitado por el padre José Dimas Soberal Díaz. ${ }^{176}$ Siguiendo la

\footnotetext{
${ }^{171}$ Lozada Montañez, Militza, 2010: 7-8.

172 Ibídem, 21.

${ }^{173}$ Ibídem, 35-41.

${ }^{174}$ Ibídem, 33.

${ }^{175}$ Declaración jurada de Bernardo del Valle Nieves notarizada por la licenciada Felicita Pérez de Torres el 2 de febrero de 1985 en ABH.

${ }^{176}$ Lozada Montañez, Militza, 2010: 80 y 85-86.
} 
misma línea la autora señala una serie de «mitos» que los libros de Negretti y de la Sra. Reyes contienen. Basada en el Diccionario de la Lengua Española la autora definió mito como aquellas cualidades atribuidas a la persona o cosas que carecen de ellas. ${ }^{177}$ En el caso del texto del padre Reyes Maldonado, ella señaló como mitos algunos de los ya señalados por Soberal Díaz en su escrito inédito. Algunos de ellos los podríamos refutar con evidencia documental, pero lo omitimos por no ser pertinente y por no alargar este artículo. En el caso de Negretti y de la señora Reyes, la autora calificó de mitos algunos actos que «Vuestra Madre» realizó según los testigos. Ejemplo de ellos son: no mojarse bajo la lluvia, mandar a callar a los pájaros y caminar a seis pulgadas del suelo. ${ }^{178} \mathrm{El}$ texto de Lozada Montañez resulta ambivalente, desde una perspectiva católica, al denominar mito a esos fenómenos, porque tiene un carácter eclesial oficial al venderse en el Santuario pro fondos del mismo, por haber sido la tesina dirigida por el rector del lugar y contar con el aval del obispo de la diócesis, y en aquel momento Presidente de la Conferencia Episcopal Puertorriqueña, Mons. Rubén Antonio González Medina. Sucede que si extrapolamos su sistema de interpretar y catalogar los mitos podríamos decir que los fenómenos místicos narrados en las hagiografías y en las Sagradas Escrituras son un mito.

La antropóloga Mercedes López-Baralt expone que el mito hay que estudiarlo en su contexto, de lo contrario es estéril. Para su estudio es indispensable tener en cuenta la historia, la lingüística, la arqueología, entre otras disciplinas. ${ }^{179}$ Por otro lado, el historiador Mircea Elide expuso que la única manera de desmitificar un suceso es a través de la disciplina de la historia. ${ }^{180}$ De la lectura del libro, se desprende claramente que ésta no fue tomada suficientemente en cuenta, pues solamente se revisó alguna literatura y se realizaron entrevistas. En ningún lugar del texto se indica que se investigaron fuentes primarias. No obstante, todos los testigos de los acontecimientos ya fallecieron, lo mismo que muchos de los hijos de éstos, ${ }^{181}$ imposibilitando así la historia oral con aquellos testigos oculares tal como lo exige la metodología. ${ }^{182}$

Por otro lado, la prensa de la época menciona que en el barrio Espino de San Lorenzo corría el rumor de que «Vuestra Madre» realizaba milagros, al punto de

${ }^{177}$ Ibídem, 33, 79, 81, 87 y 90, notas 23, 172, 174, 180-181 y 199-200.

${ }^{178}$ Ibídem, 87-90.

${ }^{179}$ López-Baralt, Mercedes, 1985. El mito taíno: Levi-Strauss en las antillas: 43. Río Piedras, Puerto Rico; Ediciones Huracán, Inc.

${ }^{180}$ Eliade, Mircea, 1968: 128.

${ }^{181}$ Reyes, Jaime M. F., 1991: 95, nota \#7; Negretti, Vionette G., 2005: 9.

${ }^{182}$ Enríquez Seiders, Sandra A., 2010 «La historia oral como materia prima para escribir historia de mujeres» en Carmelo Rosario Natal, (coordinador), La biografía en Puerto Rico: ensayos sobre historia, teoría, praxis, metodología: 154-155. San Juan, Puerto Rico, Ediciones Puerto.

Hispania Sacra, LXVI

134, julio-diciembre 2014, 689-731, ISSN: 0018-215X, doi: 10.3989/hs.2014.066 
que fue tildada de embaucadora. ${ }^{183}$ En este sentido los hechos catalogados como mito por Lozada Montañez fueron vistos como hechos reales por los seguidores de «Vuestra Madre»y esto es constatado en las fuentes primarias y en el testimonio oral de sus discípulos, recogidos por el presbítero Reyes Maldonado. En síntesis, el estudio realizado por Militza Lozada Montañez esta viciado y sus conclusiones son erradas.

El mito en torno a «Vuestra Madre» tomó más fuerza cuando el 4 de abril de 2013 el periodista Efrén Arroyo presentó un reportaje televisivo sobre el asunto a través de Wapa-TV, uno de los principales canales de televisión de Puerto Rico. En él expuso que creyentes del carácter sobrenatural de esta mujer le pedían a la Iglesia que reabriera la investigación del caso que se encontraba cerrado por falta de evidencia. Se presentó a Gerardo González Rosario, nieto de una de las personas que conoció a «Vuestra Madre», quien afirmó que por instrucciones de ella fue a la Santa Montaña a desenterrar unos frascos que contenían su sangre para enterrarlos en otro lugar. De uno de ellos tomó una muestra que actualmente conserva. Esta muestra fue sometida a un laboratorio para análisis del ADN. Según los resultados la sangre pertenece a una mujer y son tan antiguos que no pertenecen a una persona contemporánea. Por otro lado, Arroyo expuso que la sangre no se había coagulado ni cambiado de color a pesar de tener más de cien años. Este hecho es expuesto en varias declaraciones juradas. En el reportaje se expuso que el asunto era abordado en un nuevo libro de la periodista Vionette G Negretti intitulado: ¿Lobos o ungidos? ${ }^{184}$ El reportaje fue utilizado para promocionar el libro de Negretti y ejercer presión sobre la jerarquía para que tome cartas en el asunto.

El nuevo texto de Negretti se puede divir en tres partes. La primera es un resumen de su libro anterior La buenaventura.${ }^{185} \mathrm{La}$ segunda es un recuento de diversos sucesos relacionados con la publicación de su libro y la alegada conspiración para desbancar a Mons. Enrique Hernández Rivera ocurridos desde el 2005 hasta el 2013. El más trascendental es el testimonio de González Rosario acerca del hallazgo de la supuesta sangre de «Vuestra Madre» en 1985 y los resultados del análisis que se le hizo en el local de Advance DNA Identification Center, Inc. ${ }^{186}$ En esta segunda parte de su libro destruye la hipótesis de Soberal Díaz presentando el acta de defunción de Elena Huyke. Asimismo, mina la credibilidad

${ }^{183}$ Boletín Mercantil de de Puerto Rico, 20 de mayo de 1904, 2; 17 de diciembre de 1906, 4; El Águila de Puerto Rico, 30 de abril de 1907, 6.

${ }^{184}$ Efrén Arroyo, «Piden a la Iglesia Católica reevaluar caso. El caso de la llamada montaña santa de la madre Elenita de Jesús, mujer ya fallecida que alegan hizo prodigios y cambió la vida de muchas personas.» en http://www.wapa.tv/noticias/especiales/piden-a-la-iglesia-catolica-reevaluarcaso_20130404212948.html (consultado el 13 de abril de 2013).

${ }^{185}$ Negretti, Vionette G., 2013. ¿Lobos o ungidos?: 3-19. San Juan, P. R., Tropic Ads.

${ }^{186}$ Ibídem, 21-180. 
del informe refutando algunos de sus planteamientos. ${ }^{187}$ También aborda el texto de la señora Reina I. Reyes planteando que sus alegaciones son desacertadas e intenta mostrar en qué falló y porqué. ${ }^{188}$ Sobre la acusación que la señora Reyes le hizo, y que abordé en este artículo, guarda un rotundo silencio. Otro de los textos sobre el cual ejerce su crítica es el de Lozada Montañez. Negretti cuestiona la metodología empleada por ella y el hecho de no haber entrevistado al padre Reyes Maldonado. En su afán por contradecir a Lozada Montañez transcribe una entrevista al referido presbítero donde echa por tierra los planteamientos de esta última ${ }^{189}$ En la tercera parte Negretti transcribe de forma parcial el texto del sacerdote Reyes Maldonado, el informe de Soberal Díaz, entre otros documentos. ${ }^{190} \mathrm{La}$ autora finaliza exponiendo que González Rosario le informó al Obispo de Caguas acerca de la existencia de la sangre. Negretti asegura que su libro provee al Prelado evidencia perital, legal y científica sobre la posible identidad de «Vuestra Madre». Sostiene que si eventualmente el Obispo se rehusara a abrir la investigación, la Conferencia Episcopal Puertorriqueña debiera tomar cartas en el asunto. ${ }^{191}$

El escrito de Negretti, al carecer de una metodología rigurosa contiene planteamientos dudosos. Por ejemplo, para tratar de minar la credibilidad de la Sra. Reyes - que por lo demás no incide en sus plantamientos - expuso:

...la Colección Puertorriqueña de la Universidad de Puerto Rico, (localizada en el segundo piso de la Biblioteca Lázaro del recinto de Río Piedras,) la cual preserva todos los periódicos publicados en Puerto Rico desde la llegada de la Imprenta a la isla, no contiene un solo periódico o revista que indique que hubo un fuego en el casco urbano de San Lorenzo en $1937 .{ }^{192}$

Sin embargo, la realidad es que el periódico El Mundo reseñó un fuego que ocurrió el 31 de mayo de dicho año en la alcaldía de dicho municipio. El siniestro destruyó la documentación del municipio y el edificio de madera que servía de alcaldía. Las pérdidas ascendieron a $\$ 25,000$ dólares. Durante el fuego se temió que se propagara a la farmacia de Juan Sellés, hijo, que estaba localizada cerca del incendio. Por este motivo hubo que aplicar agua dentro de la botica, dañando los medicamentos que en ella se encontraban. ${ }^{193}$

\footnotetext{
${ }^{187}$ Ibídem, 63-68, 123-144.

${ }^{188}$ Ibídem, 44-59.

${ }^{189}$ Ibídem, 78-88.

${ }^{190}$ Ibídem, 201-413.

${ }^{191}$ Ibídem, 181.

192 Ibídem, 52.

193 «El ayuntamiento de San Lorenzo destruido por un fuego en la madrugada de ayer» en El Mundo, 1 de junio de 1937,4 .

Hispania Sacra, LXVI

134, julio-diciembre 2014, 689-731, ISSN: 0018-215X, doi: 10.3989/hs.2014.066
} 
En la bibliografía de su libro Negretti afirma que hizo una búsqueda exhaustiva, es decir día a día, mes por mes de todas la ediciones de los periódicos de 1937 en dicha sala entre mayo a junio de $2010 .{ }^{194}$ En este punto hace falta mayor rigurosidad: primero porque existe evidencia de un fuego en ese año y el ejemplar se encuentra en dicha biblioteca. Segundo, la fecha en que alega que estuvo investigando coincidió con la Huelga Universitaria de 2010. Esta comenzó en abril y se extendió hasta 21 de junio del mismo año. Durante ese proceso la Universidad estuvo cerrada por sesenta y dos días. No fue hasta el 30 de junio que el Recinto abrió sus puertas a fin de comenzar los preparativos para reanudar las labores administrativas y académicas. ${ }^{195}$

La Colección Puertorriqueña de la Universidad de Puerto Rico no conserva todos los periódicos desde la llegada de la imprenta a Puerto Rico pues hay muchas colecciones incompletas, títulos inexistentes y ejemplares conservados en otras bibliotecas y archivos. En este punto la autora también resulta contradictoria pues si bien es cierto que ella afirma que todos los periódicos del país se encuentran allí depositados, ${ }^{196}$ en otro lugar del texto expone que visitó varias bibliotecas buscando un ejemplar de un periódico que menciona Soberal Díaz. ${ }^{197}$

\section{CONCLuSIÓN}

A fines del siglo XIX vivió una mujer en Puerto Rico que las personas conocieron como «Vuestra Madre». ¿Quién fue? Aun hoy día existen múltiples teorías sobre su identidad. Luego de analizar todas las versiones existentes hasta el momento sobre la identidad de esta mujer, nuestro estudio revela, que entre ellas la expuesta por el licenciado Ramón Fortuño Sellés, resulta la más coherente. Sin embargo, es menester investigar con más profundidad el asunto con miras a esclarecer definitivamente su identidad. Como «Vuestra Madre» se autoproclamó la Virgen María, se fue desarrollando un mito alrededor de su persona. La crisis desatada por la invasión estadounidense junto a la sed del campesinado de tener una experiencia personal de Dios en su vida, hicieron que creyeran sin lugar a dudas que «Vuestra Madre» era la Virgen María La mentalidad del jíbaro necesitaba apoyo y ayuda que le brindara las herramientas necesarias para superar la crisis de 1898 y poder estabilizarse. En el caso de ellos, «Vuestra Madre» fue la líder carismática que los ayudó en el difícil

\footnotetext{
${ }^{194}$ Negretti, Vionette G., 2013: 417.

${ }^{195}$ López Cabán, Cynthia, «Termina la huelga de estudiantes en la UPR» en El Nuevo Día, 22 de junio de 2020, p. 10; (de la misma autora), «Abre a medias el Recinto de Río Piedras de la UPR» en El Nuevo Día, 1 de julio de 2020, p. 22.

${ }^{196}$ Negretti, Vionette G., 2013: 28, 52.

${ }^{197}$ Ibídem, 143 y 417.
} 
proceso de transición de un régimen autonómico a uno colonial estadounidense. Su ayuda provino desde la misma religiosidad popular junto a fantasías e ilusiones míticas. Luego de su muerte, la Iglesia Católica se encontró impotente para encauzar el movimiento debido a la pobre y escasa evangelización que pudo efectuar en el área. A pesar de que el mito corría de boca en boca, la jerarquía no lo veía como un problema mayor, además no podía frenarlo, en ocasiones, se hizo de la vista larga. Esta realidad cambió drásticamente con la publicación del libro del sacerdote benedictino, Jaime Reyes Maldonado. Dicha publicación sacó a la luz pública lo que el pueblo sencillo había vivido a través de los años, sin cuestionarse, de acuerdo a su religiosidad popular. Mientras, la Iglesia Católica trató, por todos los medios a su alcance, de frenar y erradicar la creencia de que «Vuestra Madre» es la Virgen María. Además, el asunto quedó en la incógnita y siguen las suposiciones hasta el presente, lo cual representa un verdadero reto a la jerarquía de la diócesis de Caguas. La hipótesis y nuevas perspectivas aquí presentadas deben ser tomadas en consideración para futuras investigaciones.

BiBLIOGRAFÍA

\section{A. Fuentes primarias}

1. Manuscritas

a. Archivo General de Puerto Rico.

1) Fondo: Departamento de Estado

a) serie: Declaraciones de Nacionalidad

b. Archivo Histórico Arquidiocesano

1) Archivo Histórico Diocesano

a) Fondo Diocesano: Sección Gobierno

(1) Serie: Correspondencia

(2) Serie: Libro biográfico del clero

c. Archivo Parroquial de Nuestra Señora de las Mercedes del pueblo de San Lorenzo

1) Libro de bautismos tomo 17

d. Archivo del padre Jaime M. F. Reyes, OSB en la Abadía Benedictina de Humacao 


\section{Impresas}

Carroll, Henry King, 1975. Report on the Island of Porto Rico, Its Population, Civil Government, Commerce, Industries Production, Roads, Tariff, and Currency, with Recommendations. Nueva York, EE. UU., Arno Press.

Novena de la Purísima Virgen María de la Merced, y Misericordia, Redentora de los cautivos. Para implorar su gran protección en cualquier necesidad espiritual ó temporal. San Juan, Tip. De González \& Co., 1888.

Valle Atiles, Francisco del, 1887. El campesino puertorriqueño sus condiciones físicas, intelectuales y morales, causas que las determinan y medios para mejorarlas: 128. San Juan, P. R., Tip. de José González Font.

\section{Prensa}

El Águila de Puerto Rico, 1907,

Boletín Eclesiástico de la Diócesis de Puerto Rico, 1910.

Boletín Mercantil de Puerto Rico, 1889, 1904.

Boletín Parroquial de Guayama, Pto-Rico, 1917.

El Defensor Cristiano, 1906.

El Ideal Católico, 1901.

El Iris de Paz, 1902.

El Nuevo Día, 2004.

La Conciencia Libre, 1911.

La Correspondencia de Puerto Rico, 1894-1910.

La Democracia, 1894.

La Verdad, 1913

Puerto Rico Ilustrado, 1927, 1929.

San Juan News, 1904.

\section{Noticias}

A diestro y siniestro» en La Democracia, 22 de agosto de 1903, p 4.

«Confirmase la sospecha de que la «Virgen» aparecida en Quebradillas es un caso de alucinación histérica» en La Correspondencia de Puerto Rico, 24 de agosto de 1903, 4. 
«El ayuntamiento de San Lorenzo destruido por un fuego en la madrugada de ayer» en El Mundo, 1 de junio de 1937, p. 4.

«Hay en Patillas una religiosa que predica el evangelio» en La Correspondencia de Puerto Rico, 21 de diciembre de 1903, p. 4.

«Quebradillas» en La Correspondencia de Puerto Rico, 26 de agosto de 1903, p. 2.

«Raros sucesos en Patillas. Feligreses de un culto que llaman de la "Santa Montaña."» en La Correspondencia de Puerto Rico, 11 de mayo de 1910, p. 1.

«Se dijo en Quebradillas que una Virgen se había mostrado de pié sobre una pena [sic] con una paloma en la mano» en La Correspondencia de Puerto Rico, 21 de agosto de 1903 , p. 1

«Una inspirada por la Vírgen (sic) en San Lorenzo» en La Correspondencia de Puerto Rico, 16 de diciembre de 1906, p. 1.

«"Yo la Admirable y Respetable Madre Redentora del Universo". Así se moteja ella misma una mujer de Patillas, en el barrio de Rio (sic) Arriba» en La Correspondencia de Puerto Rico, 7 de abril de 1908, p. 3.

\section{B. Fuentes Secundarias}

\section{Impresas}

Abad Ibáñez, J. A. y M. Garrido Bonaño, 1997. Iniciación a la liturgia de la Iglesia. Madrid, España, Ediciones Palabra.

Agosto Cintrón, Nélida, 1998. «Género y discurso religioso en un movimiento carismático en Puerto Rico: la Madre Elenita de la Montaña Santa» en Silvia Álvarez Curbelo, Mary Frances Gallart, Carmen I. Rafucci, (eds.) Los arcos de la memoria: el '98 de los pueblos puertorriqueños: 193-207. San Juan, P. R., Editorial Postdata.

Alarcia, R., «Desde San Lorenzo» en La Milagrosa, 11 de abril de 1929, año VIII, núm. 108, pp. 8-9.

Aráez y Ferrando, Román, 1905. Historia del ciclón del día de San Ciriaco. Resúmen (sic) general de cuanto fué (sic) observado por el autor de esta obra, y publicado por la prensa periodística de la Isla de Puerto Rico, sobre lo acontecido en esta el 8 de agosto de 1899, en que pasó un terrible huracán, resultando la muerte violenta de 2.184 de sus habitantes é hiriendo 2.764, más causando daños materiales en la propiedad por valor de \$35.889,013, San Juan, P. R., Heraldo Español.

Asenjo, Conrado, 1941-1942. «Quien es quien en Puerto Rico». Diccionario biográfico de récord personal. San Juan, P. R., Cantero Fernandez \& Co.

Bernabe, Rafael, 1996. Respuestas al colonialismo en la política puertorriqueña 1899-1929. Río Piedras, P. R., Ediciones Huracán, Inc. 
Cambell, Michael «"Imperialismo sin un imperio colonial”: misioneros protestantes en Puerto Rico: 1898-1914» en Ricardo R. Camuñas (ed.), El impacto del 1898 en el oeste puertorriqueño: 65-77. San Juan, P. R., Librería y Editorial Ateneo Puertorriqueño.

Canino Salgado, Marcelino y Carmen Chiesa de Pérez, 1983. Leyendas puertorriqueñas para niños. Hato Rey, PR.: Editorial Juvencia.

Carol, Juniper B., 1964 «Corredención de nuestra Señora» en. B. Carol, Mariología: 760-804. Madrid, España, Biblioteca de Autores Cristianos.

Carrillo, Salvador, 1988. «El mensaje teológico de Guadalupe» en Nuestra Señora de América. Homenaje del CELAM a la Santísima Virgen, con motivo del Año Mariano, tomo II: 51-98. Bogotá, Colombia, Consejo Episcopal Latinoamericano (CELAM).

Carroll, Eamon R., 1964. «María en el magisterio de la Iglesia» en J. B. Carol, Mariología: 5-53. Madrid, España, Biblioteca de Autores Cristianos.

Catecismo de la Iglesia Católica. Santo Domingo, República Dominicana, Librería Juan Pablo II, 1992.

Cifre de Loubriel, Estela, 1962. Catálogo de extranjeros residentes en Puerto Rico en el siglo XIX. Río Piedras, P. R.: Ediciones de la Universidad de Puerto Rico.

Colombás, García M., 1974. El monacato primitivo. Hombres, hechos, costumbres, instituciones, tomo I. Madrid, España, Biblioteca de Autores Cristianos de La Editorial Católica, S. A.

Código de Derecho Canónico. Edición bilingüe comentada por los profesores de la facultad de Derecho Canónico de la Universidad Pontificia de Salamanca. Madrid, España, Biblioteca de Autores Cristianos, 1984.

Concilio Vaticano II. Constituciones, decretos, declaraciones, legislación posconciliar. Madrid, España: Biblioteca de Autores Cristianos, 1967.

Delgado Cintrón, Carmelo, 1988. Derecho y colonialismo. La trayectoria histórica del derecho puertorriqueño: ensayos. Río Piedras, P. R., Editorial Edil, Inc.

Eliade, Mircea, 1968. Mito y realidad. Madrid, España, Ediciones Guadarrama, S. A.

Enríquez Seiders, Sandra A., 2010 «La historia oral como materia prima para escribir historia de mujeres» en Carmelo Rosario Natal, (coordinador), La biografía en Puerto Rico: ensayos sobre historia, teoría, praxis, metodología: 149-165. San Juan, Puerto Rico, Ediciones Puerto.

Fortuño Janeiro, Luis, 1963. Álbum histórico de Ponce. Contentivo de los más importantes datos históricos y de una exposición gráfica de su cultura y progreso. Ponce, $\mathrm{P}$. R., Imprenta Fortuño.

Fortuño Sellés, Ramón, «Elena Ache «Vuestra Madre"» en El Mundo, 19 de junio de 1935,9 y 15 .

García Paredes, José Cristo Rey, 2001. Mariología. Madrid, España, Biblioteca de Autores Cristianos. 
Gómez Carillo, E. «Introducción» en Paladius, Los padres del desierto: V-XXIX. París, Francia, Casa Editorial Garnier Hermanos.

González, Carlos Ignacio, 1989. María Evangelizada y Evangelizadora. Bogotá, Colombia, Consejo Episcopal Latinoamericano (CELAM).

González Mendoza, Juan R., 2002. «Revolución ecológica y desarrollo de las haciendas en San Germán, 1750-1850» en Mario R. Cancel y Héctor R. Feliciano Ramos, (editores). Invitación a la historia regional: 36-82. San Juan de Puerto Rico, Asociación Puertorriqueña de Historiadores, Postdata.

Gould, Lyman J., 1975. La Ley Foraker. Raíces de la política colonial de los Estados Unidos. Río Piedras, P. R., Editorial Universitaria U. P. R.

Hernández Aponte, Gerardo Alberto, 2010. El espiritismo de Allan Kardec en Puerto Rico 1860-1907. Tesis doctoral, Río Piedras, Universidad de Puerto Rico, Departamento de Historia.

-, 2013. La Iglesia Católica en Puerto Rico ante la invasión de Estados Unidos de América. Lucha, sobrevivencia y estabilización: (1898-1921). San Juan, Puerto Rico: Academia Puertorriqueña de la Historia y Decanato de Estudios Graduados e Investigación (DEGI) de la Universidad de Puerto Rico, Recinto de Río Piedras.

Hernández Rivera, Mons. Enrique «Nota aclaratoria. En cada revisión está la fuerza del Espíritu» en El Visitante, 14 de agosto de 1993, 18.

Homilía del Santo Padre Benedicto XVI, 13 de mayo de 2010 en la explanada del Santuario de Fátima como parte del Viaje Apostólico a Portugal en el $10^{\circ}$ aniversario de la beatificación de Jacinta y Francisco, los pastorcillos de Fátima (11-14 de mayo de 2010). Consultada en http://www.vatican.va/

Lebrón Rivera, Rafael, 1990. ¡Detengamos el jinete de la muerte!: la lucha por controlar la tuberculosis en Puerto Rico, 1900-40... Tesis de Maestría, Río Piedras, Universidad de Puerto Rico, Departamento de Historia.

Linse, Ulrich, 2002. Videntes y milagreros. La búsqueda de la salvación en la era de la industrialización. Madrid, España, Siglo XXI de España Editores, S. A.

Llorca, Bernardino, Ricardo García-Villoslada, Francisco Javier Montalbán, 1966. Historia de la Iglesia Católica en sus cuatro grandes edades: Antigua, Media, Nueva, Moderna, tomo I. Madrid, España, Biblioteca de Autores Cristianos.

López-Baralt, Mercedes, 1985. El mito taíno: Levi-Strauss en las antillas. Río Piedras, Puerto Rico; Ediciones Huracán, Inc.

López Cabán, Cynthia, «Abre a medias el Recinto de Río Piedras de la UPR» en El Nuevo Día, 1 de julio de 2020, 22.

—, «Termina la huelga de estudiantes en la UPR» en El Nuevo Día, 22 de junio de 2020, 10 .

Hispania Sacra, LXVI

134, julio-diciembre 2014, 689-731, ISSN: 0018-215X, doi: 10.3989/hs.2014.066 
Lozada Montañez, Militza, 2010. Un siglo de historia, mitos, creencias y tradiciones religiosas de la Montaña Santa. Santo Domingo, República Dominicana, Amigo del Hogar.

Maldonado Miranda, Vivian «"El hermano del beato cambió mi vida"» en $E l$ Visitante, 25 de abril al 1 de mayo de 2010,14.

McGuire, Vicente, 1965. Mosaico cagüeño. Recuerdos de la Parroquia del Dulce Nombre de Jesús Caguas, Puerto Rico. San Juan, P. R., Cooperativa de Artes Gráficas Romualdo Real.

Muckley, Robert L. y Adela Martínez-Santiago, 1978. Leyendas de Puerto Rico: a Collection of Puerto Rican Legends. Illinois, EE. UU., National Textbook Company.

Mujica Pinilla, Ramón, 2001. Rosa limensis. Mística, política e iconografía en torno a la patrona de América. Lima, Perú, Instituto Francés de Estudios Andinos; Fondo de Cultura Económica S. A. de C. V.; Banco Central Reserva del Perú.

Negretti, Vionette G., 2005. La buenaventura. San Juan, P. R., Ediciones Yagumbro.

—, 2013. ¿Lobos o ungidos? San Juan, P. R., Tropic Ads.

Paladius, Los padres del desierto. París, Francia, Casa Editorial Garnier Hermanos.

Pantojas García, Emilio, [1973-1985?]. La iglesia protestante y la americanización de Puerto Rico, 1898-1917. Bayamón, P. R., Prisa.

Pastor Ruiz, Justo, 1947. Vieques antiguo y moderno. 1493-1946. Yauco, Puerto Rico, Tipografía Rodríguez Lugo.

Picó, Fernando, 1997. «De Póver a Págüer: La configuración del personaje en la narrativa histórica en Puerto Rico» en Carmen Cazurro García de la Quintana y Mario R. Cancel Sepúlveda (eds.), Enfoques generacionales/Rumbos postmodernos: 37-50. Aguadilla, P. R., Quality Printers.

—, 1998. «El catolicismo popular en el Puerto Rico del siglo 19» en Ángel G. Quintero Rivera (ed.), Vírgenes, magos y escapularios: imaginería, etnicidad y religiosidad popular en Puerto Rico: 151-162. San Juan, P. R., Centro de Investigaciones Sociales; UPR, Río Piedras; Centro de Investigaciones Académicas; Universidad Sagrado Corazón; Fundación Puertorriqueña de las Humanidades.

- , 1994. «Religiosidad institucional y religiosidad popular en Puerto Rico en el siglo 19» en Revista Universidad de América, año 6, núm. 2, 36-38.

Quiñones Rivera, Sor Ursula y Sor Candida Quiñones Rivera, 1983. Las Hijas de la Caridad en Puerto Rico: 1863-1983. Santo Domingo, R. D., Amigo del Hogar.

Reyes, Jaime M. F., 1991. La Santa Montaña de San Lorenzo, Puerto Rico, y el misterio de Elenita de Jesús (1899-1909). México, Tipografías Editoriales.

Reyes, Reina I., 2007. ¡Soy Vuestra Madre! No me persigas. [s.1.: s.e.].

Rivera Arbolay, Pedro J., 1977. Patillas, la esmeralda del sur. San Juan, P. R., Cooperativa de Artes Gráficas «Romualdo Real». 
Rivera Ramos, Efrén, 2001. The Legal Construction of Identity: the Judicial and Social Legacy of American Colonialism in Puerto Rico. Washington, DC, EE. UU.: American Psychological Association.

Rivera Rivera, Antonia, 1995. El estado español y la beneficencia en el Puerto Rico del siglo XIX. Republica Dominicana, Editorial El Cuervo Dorado.

Robichaud, Armand J. 1964 «María, dispensadora de todas las gracias» en en J. B. Carol, Mariología: 805-837. Madrid, España, Biblioteca de Autores Cristianos.

Rodríguez, Paulino, 1939. Cataratas de ensueños, agosto de 1927. Don Pepillo -1920 - y Elena, la misionera, 1935. Novelas cortas en 1 tomo. Aire netamente criollo. Cayey, P. R., Imprenta Morales.

—, 1967. Historia del pueblo de Patillas. Hato Rey, P. R., Ramallo Bros. Printing, Inc.

Rodríguez Escudero, Néstor A., 1994. El angustioso enigma de la muerte, su más razonable hipótesis: el espiritismo kardeciano científico. Quebradillas, P. R., Imprenta San Rafael.

Rodríguez León, Mario A., 1990. Los registros parroquiales y la microhistoria demográfica en Puerto Rico. San Juan, P. R.: Centro de Estudios Avanzados de Puerto Rico y el Caribe.

Román, Reinaldo L., 2007. Governing Spirits. Religion, Miracles, and Spectacles in Cuba and Puerto Rico, 1898-1956. North Carolina, EE.UU.: The University of North Carolina Press.

Rosario Rivera, Raquel (ed.), 2000. La llegada del cíclope: percepciones de San Ciriaco a cien años de su visita. San Juan, P. R., Fundación Puertorriqueña de las Humanidades.

Sáez, José Luis, 1994. La Iglesia y el negro esclavo en Santo Domingo. Una historia de tres siglos. Santo Domingo, República Dominicana, Patronato de la Ciudad Colonial de Santo Domingo.

Salivia, Luis A., 1972. Historia de los temporales de Puerto Rico y las Antillas (1492 a 1970). San Juan, P. R., Editorial Edil, Inc.

Santaella Rivera, Esteban, 1979. Historia de los Hermanos Cheos. Recopilación de escritos y relatos. Santo Domingo, República Dominicana, Editora «Alfa y Omega»

-, 2003 Historia de los Hermanos Cheos. Recopilación de escritos y relatos. Rincón, P. R., MB Publishers de Puerto Rico.

Sarramía, Tomás, 1999. Lealtad y nacionalidad. Catálogo de catalanes, valencianos y baleares residentes en Puerto Rico tras el cambio de soberanía de 1898. San Juan, P. R., PR Books.

Silva Gotay, Samuel, 1997. Protestantismo y política en Puerto Rico 1898-1930: hacia una historia del protestantismo evangélico en Puerto Rico. Río Piedras, P. R., Editorial de la Universidad de Puerto Rico.

Soberal, José Dimas, «La Santa Montaña» en El Vocero, 14 de julio de 1994, 49.

Hispania Sacra, LXVI

134, julio-diciembre 2014, 689-731, ISSN: 0018-215X, doi: 10.3989/hs.2014.066 
—, 1994. La Santa Montaña: investigación realizada para la Conferencia Episcopal Puertorriqueña. Bayamón, P. R., texto inédito en los archivo del padre Jaime M. F. Reyes, OSB en la Abadía Benedictina de Humacao.

Schwartz, Stuart B., 1992. «El huracán de San Ciriaco: Desastre, política y sociedad en Puerto Rico 1899-1901» en Historia y Sociedad, año 5, 1992: 128-162.

Suárez López, Jesús, 2009. Cuentos medievales en la tradición oral de Asturias. Asturias, España, Red de Museos Etnográficos de Asturias

Trías Monge, José, 1980-1994. Historia constitucional de Puerto Rico: V volúmenes, Río Piedras, P. R., Editorial Universitaria.

—, 1999. Puerto Rico, las penas de la colonia más antigua del mundo. Río Piedras, P. R., Editorial de la Universidad de Puerto Rico, 1999.

«Un siglo de historia, mitos; creencias y tradiciones religiosas de la Montaña Santa» en El Visitante, 11 al 17 de octubre de 2009, 21.

Vázquez González, Ángel M., 1986. El Paso por la Vega. México, Editorial Tierra Firme, S. A., de C. V.

Vicario, Francisco, 1909. «Apuntes para la historia de la Congregación de la Misión en la isla de Puerto Rico» en Anales de la Congregación de la Misión fundada por San Vicente de Paúl, tomo XVII: 583-626, Madrid, España, Imprenta del Asilo de Huérfanos del S. C. de Jesús

Vidal, Teodoro, 2010. Oraciones, conjuros y ensalmos en la cultura popular puertorriqueña. San Juan P. R., Ediciones Alba.

—, 1989. Tradiciones en la brujería puertorriqueña. San Juan P. R., Ediciones Alba.

Westmeier, Karl-Wilhelm, 2000. El dolor y la gloria: una historia de la Alianza Cristiana y Misionera en Puerto Rico. Philadelphia, EE. UU., Christian Publications Inc.

\section{2. documental}

«La Santa Montaña. Santuario de la Virgen del Carmen.», documental preparado por la Oficina de Medios de Comunicación Social (OMECOS) de la Diócesis de Caguas, Puerto Rico, 1995.

\section{Reportaje televisivo}

Arroyo, Efrén, «Piden a la Iglesia Católica reevaluar caso. El caso de la llamada montaña santa de la madre Elenita de Jesús, mujer ya fallecida que alegan hizo prodigios y cambió la vida de muchas personas.» en http://www.wapa.tv/noticias/especiales/ piden-a-la-iglesia-catolica-reevaluar-caso_20130404212948.html (consultado el 13 de abril de 2013). 